Published in Metallurgical and Materials Transactions B, volume 31b, april 2000, pp. 391-402. doi:10.1007/s11663-000-0057-4.

This paper (and Part I) received TMS Champion H. Mathewson Award 2003 as the best paper of the year 2000 published in MMTB

\title{
Coal Pyrolysis in a Rotary Kiln. Part 2: Overall Model of the Furnace
}

\author{
Fabrice PAtisson, Etienne Lebas, François Hanrot, \\ Denis ABLitZER AND JEAN-LEON HouZELOT
}

\begin{abstract}
In order to simulate coal pyrolysis in a rotary kiln in the steady state regime, a mathematical model has been developed which calculates the temperature profiles in the charge, the gas and the furnace walls, together with the gas composition and the degree of removal of volatile species. The model takes into account the principal physicochemical and thermal phenomena involved, including the complex movements of the charge, the gas flow, heat transfer between the charge, the gas phase and the furnace walls, drying and pyrolysis of the coal, the cracking of tars, the combustion of volatile species, and the combustion and extinction of the coke. The data necessary for the model were obtained by specific experiments or from the literature. The model has been validated by comparing its predictions with measurements performed on an industrial rotary kiln. The model has been used to study the influence of operating parameters such as the furnace rotation speed, in order to optimize the process. It is shown how a modification to the extinction zone leads to an increase in coke yield of $0.75 \%$.
\end{abstract}




\section{INTRODUCTION}

Rotary kilns are widely employed in the cement, metallurgical and chemical industries due to their simplicity of use and their ability to continuously treat granular or powder solids with excellent heat and matter transfer between the solid and gas phases. The present paper considers the use of the rotary kiln for the pyrolysis of coal to produce high reactivity coke for electrometallurgical applications. The coal is introduced at one end of the furnace in the form of 1 to $2 \mathrm{~cm}$ diameter grains and flows parallel to the kiln axis, which is slightly inclined to the horizontal, due to the rotation of the tubular body. The coke produced is discharged at the other end. A counter-flow of air is introduced at the coke end, and becomes laden with volatile species evolved by the pyrolysis, while at the same time being deplenished in oxygen due to the various combustion reactions, which provide the energy necessary for the process.

The aim of the present article is to describe a complete mathematical model of the kiln intended for process optimization. The model describes all the physicochemical and thermal phenomena of importance for the process, including drying of the coal, the removal of volatiles, cracking of tars, the combustion of the volatile species, the partial combustion and extinction of the coke, the solid and gas flows, and heat transfer between the charge, the kiln walls and the gas. Although several rotary kiln simulation models have been published in the literature, ${ }^{[1-5]}$ none applies specifically to the pyrolysis of coal. Another point which distinguishes the present study from previous work is that the description of the conversion of an individual coal grain to coke led us to develop a specific kinetic and thermal model, which has been termed the grain model. The latter has been described in detail in Part $1,{ }^{[6]}$ and is incorporated in the 
overall model of the kiln presented in this second paper. After considering the movement of the charge, heat transfer and combustion phenomena, the article goes on to describe the model itself and the results obtained.

\section{MOVEMENT OF THE CHARGE}

In a rotary coal pyrolysis kiln, the charge moves in the so-called rolling mode, according to Henein's classification. ${ }^{[7]}$ In this mode, the bed of grains can be divided into two zones, corresponding to the surface of the bed, where the grains roll due to the effect of gravity, often called the active zone and composed of one or several layers of grains, and the lower part of the bed, where the solid undergoes a circular movement imposed by the kiln wall. Figure 1 schematically represents the trajectory of a grain in a rotary kiln. When the grain is in the lower part of the bed, it does not advance parallel to the kiln axis. Once it has come to the surface, it follows the line of greatest slope, which depends on the dynamic rest angle of the charge $\beta$ and on the inclination of the bed with respect to the horizontal $\theta$. The grain is then reincorporated in the bed in a random manner.

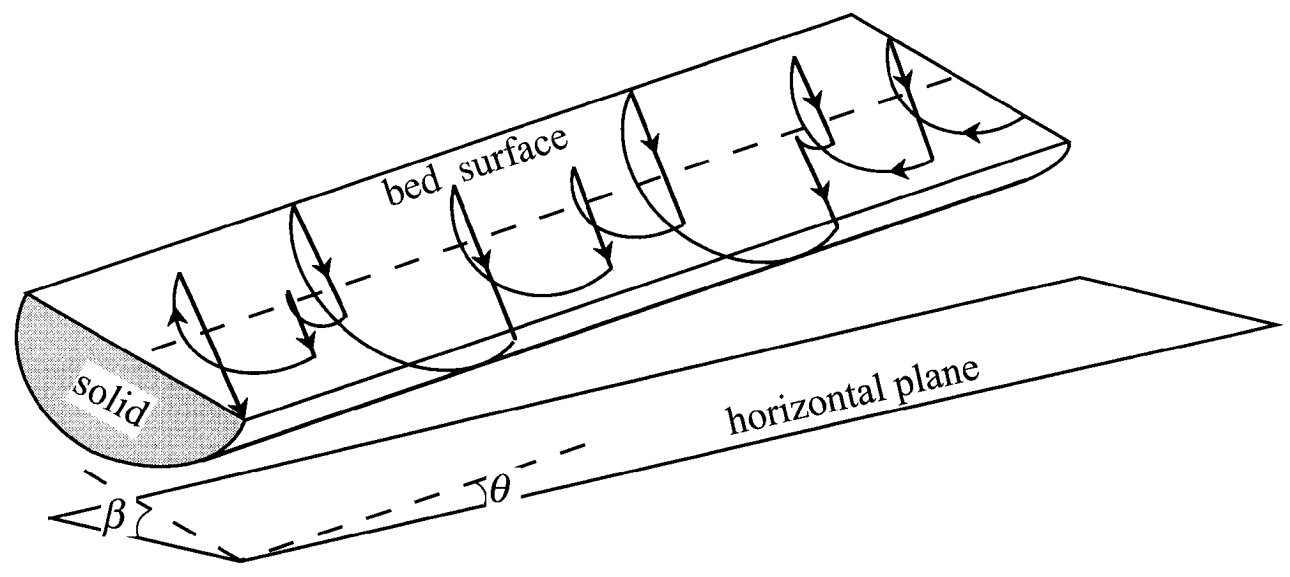

Fig. 1 - Trajectory of a grain in a rotary kiln. 
In the general case where the height of the bed $H$ varies along the axis $z$ (cf. Figure 2), the angle $\theta$ varies. The charge profile $H(z)$ generally depends on the solid flowrate and on the heights of any diaphragms present at the entrance and exit of the rotary kiln. The furnace represented in Figure 2 has an overflow feed at the entrance, while the exit is free, as in the Carling kiln (France), which was used in the present study as both a reference and a data base.
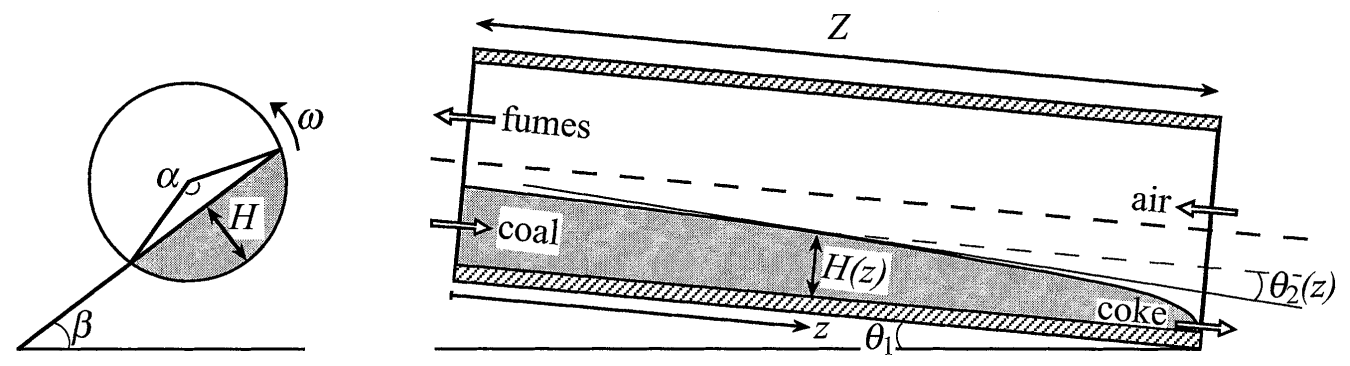

Fig. 2-Kiln sections and nomenclature.

We carried out specific investigations to gain a better understanding of the charge movements and to measure the charge flow parameters. Details of this work are given elsewhere. ${ }^{[8]}$ Only the results of direct interest for the present study will be described here. Thus, the mean residence time was determined using painted coal grains as tracers in a pilot furnace or grains of pozzolana in the industrial kiln. The fraction of time spent by the grains on the bed surface was measured in the pilot furnace by filming the successive appearances and disappearances of the painted grains, while the axial profile of the charge was established with the aid of an articulated feeler arm. This profile can be evaluated by integrating the following equation:[9]

$$
\frac{d H}{d z}(z)=\frac{\tan \theta_{1}}{\cos \beta}-\frac{12 \Phi_{V} \tan \beta}{\omega d_{w_{i}}^{3}}\left[\frac{4 H(z)}{d_{w_{i}}}-\left(\frac{2 H(z)}{d_{w_{i}}}\right)^{2}\right]^{-\frac{3}{2}}
$$


$\theta_{1}$ designates the inclination of the kiln with respect to the horizontal, $\Phi_{V}$ is the solid volume feed rate, $\omega$ is the angular rotation velocity of the kiln and $d_{w_{i}}$ is its inside diameter. The filling angle $\alpha$ is deduced from $H$ by

$$
\alpha(z)=2 \cos ^{-1}\left(1-\frac{2 H(z)}{d_{w_{i}}}\right)
$$

and the axial velocity of the charge $u$ is then given by

$$
u(z)=\frac{8 \Phi_{m}}{\alpha(z)-\sin \alpha(z)] d_{w_{i}}^{2} \rho_{a}}
$$

where $\Phi_{m}$ is the mass flowrate of solid and $\rho_{a}$ is the apparent density of the solid bed. The mean residence time $\tau$ of the grains in the kiln is obtained by integration:

$$
\tau=\int_{0}^{Z} \frac{d z}{u(z)}
$$

Finally, the formula given by Hanrot ${ }^{[10]}$ is used to calculate the average fraction of the residence time spent by the grains on the surface of the bed

$$
\frac{\tau_{s}}{\tau}(z)=\frac{8 C_{\varepsilon} \sin \frac{\alpha(z)}{2}}{\alpha(z)-\sin \alpha(z)} \frac{d_{g r}}{d_{w_{i}}}
$$

where $d_{g r}$ is the average grain diameter and

$$
C_{\varepsilon}=\sqrt[3]{\frac{\pi}{6\left(1-\varepsilon_{b}\right)}}
$$

$\varepsilon_{b}$ being the intergranular porosity of the bed

$$
\varepsilon_{b}=1-\frac{\rho_{a}}{\rho_{g r}}
$$

determined to be equal to 0.4 , for both the coal and the coke.

The use of Eqs [1] to [7] has been validated by comparing their results with measurements made in a pilot furnace. ${ }^{[8]}$ 
A final point concerning the charge flow is that the axial flow of the charge can be assimilated to a pure piston flow. ${ }^{[8]}$

\section{HEAT TRANSFER}

Heat transfer mechanisms play an essential role in the rotary kiln coal pyrolysis process. In terms of heat transfer, the furnace can be considered as a gas/solid counterflow exchanger. In the major part of the kiln, the gas is the source of energy, heating both the solid and the furnace wall. The latter acts as a regenerator, since as it rotates, it is reheated in contact with the gas, then gives up part of this energy when it passes beneath the solid. Towards the end of the kiln, on the coke side, it is the charge which represents the source of energy and heats both the gas and the kiln wall. All along the kiln, part of the heat received by the wall is dissipated to the external atmosphere.

The heat transfer between the gas, the solid and the wall involves radiation, convection and conduction (Figure 3). Because of the high temperature of the gas, above $1000^{\circ} \mathrm{C}$ over a large part of the kiln, radiation from the gas to the solid $\Phi_{r_{g s}}$ represents a significant source of energy. Radiation from the gas to the wall $\Phi_{r_{g w}}$ and from the wall to the solid $\Phi_{r_{w s}}$ must also be taken into account. Radiation from the wall to itself is negligible (§III.D). Convective heat transfer processes include the gas/wall $\Phi_{c_{g w}}$ and gas/solid $\Phi_{c_{g s}}$ exchanges. The regeneration process involves conduction and radiation from the wall to the solid with which it is in contact $\Phi_{c_{w s}}$. The heat losses are due to conduction through the wall and dissipation in the external atmosphere by convection $\Phi_{c_{w a}}$ and radiation $\Phi_{r_{w a}}$. 

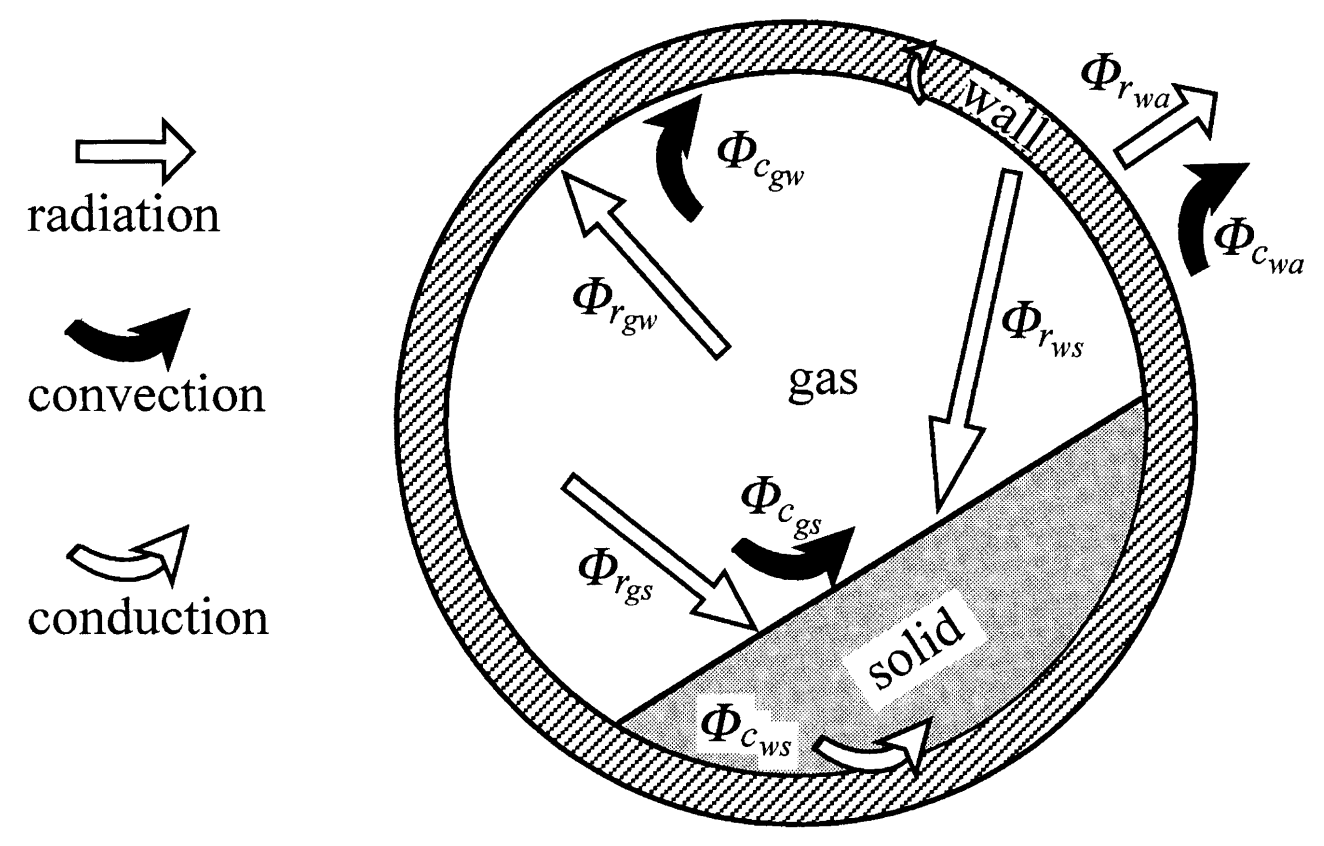

Fig. 3 - Heat fluxes in a cross section.

This description of the heat exchanges is limited to those in a section perpendicular to the kiln axis. Apart from the heat transported by the gas and the solid, longitudinal heat transfer can be neglected compared to that in the transverse direction. The manner in which the different heat fluxes in Figure 3 are calculated is described below. The objective is to consider a heat transfer model which is sufficiently complete to take into account all the phenomena mentioned above, while remaining simple enough to be readily used in the overall model of the rotary kiln. This part of the study makes use of the abundant results available in the literature on heat transfer phenomena.

\section{A. Radiation phenomena}

Calculation of the heat fluxes exchanged by radiation inside the kiln requires a knowledge of the radiative properties, particularly the emissivities, of the solid, the kiln wall and the gas, together with the choice of a radiation model. 
The emissivity $\varepsilon_{g r}$ of the coal grains during pyrolysis is poorly defined and difficult to determine, as discussed in Part $1 .{ }^{[6]}$ An accurate knowledge of the emissivity $\varepsilon_{w}$ of the refractory concrete inside kiln wall is also difficult, since coal and coke tend to become attached and diffuse into the concrete. The values used were $\varepsilon_{g r}=0.9$ et $\varepsilon_{w}=0.9$ and their influence on the results of the model is shown in $\S$ VI.A. The emissivity of the gas present in the rotary kiln depends on its concentration in absorbant species such as $\mathrm{H}_{2} \mathrm{O}, \mathrm{CO}_{2}, \mathrm{CO}$ and $\mathrm{CH}_{4}$, together with the presence of dust. In the case of a $\mathrm{H}_{2} \mathrm{O}+\mathrm{CO}_{2}$ mixture, the emissivity of the gas can be calculated from the formula ${ }^{[11]}$

$$
\varepsilon_{g}=C_{\mathrm{CO}_{2}} \varepsilon_{\mathrm{CO}_{2}}+C_{\mathrm{H}_{2} \mathrm{O}} \varepsilon_{\mathrm{H}_{2} \mathrm{O}}-\Delta \varepsilon
$$

where the emissivities of each constituent $\varepsilon_{\mathrm{CO}_{2}}$ and $\varepsilon_{\mathrm{H}_{2} \mathrm{O}}$ are calculated from their partial pressures, corrected by the coefficients $C_{\mathrm{CO}_{2}}$ and $C_{\mathrm{H}_{2} \mathrm{O}}$ which are functions of the total pressure, and where $\Delta \varepsilon$ represents a correction for overlapping of the spectral bands for the two gases. The contribution of gases other than $\mathrm{CO}_{2}$ and $\mathrm{H}_{2} \mathrm{O}$ to the emissivity of the gas phase in the rotary kiln is small, due to their low concentrations, except perhaps in the first few meters of the furnace. The contribution of dust is generally allowed for in the form of an additive emissivity term $\varepsilon_{d u s t}$, which is difficult to evaluate.

Among the models for radiation in rotary kilns proposed in the literature, the most comprehensive ones ${ }^{[12-14]}$ give a detailed description of the heat exchanges between the gas, the charge and the walls by employing the so-called n-zone method. ${ }^{[1]}$ They show that the majority of the radiative heat transfer is localized in the cross section of the furnace, the heat flux between two surfaces separated by an axial distance of more than one furnace diameter being negligible. ${ }^{[12]}$ Different simplified approaches have 
been reported in the literature. ${ }^{[15]}$ Most of the equations proposed are of the following form :

$$
\begin{gathered}
\Phi_{r_{g s}}=A_{s} E_{r_{g s}} \sigma\left(T_{g}^{4}-T_{s}^{4}\right) \quad \text { with } \quad A_{s}=d_{w_{i}} \sin \frac{\alpha}{2} \\
\Phi_{r_{g w}}=A_{w_{u}} E_{r_{g w}} \sigma\left(T_{g}^{4}-T_{w_{u}}^{4}\right) \quad \text { with } \quad A_{w_{u}}=d_{w_{i}}\left(\pi-\frac{\alpha}{2}\right) \\
\Phi_{r_{w s}}=A_{s} E_{r_{w s}} \sigma\left(T_{w_{u}}^{4}-T_{s}^{4}\right)
\end{gathered}
$$

where $\Phi_{r}$ is a radiative flux per unit length of the kiln, $A$ is an area per unit length, $\sigma$ is Stefan's constant, $T_{g}, T_{s}, T_{w_{u}}$ are the temperatures of the gas, the charge surface and the uncovered inside wall, and the coefficients $E_{r}$ are functions of the emissivities of the grains, the gas and the wall. We calculated the values of these coefficients using different correlations. ${ }^{[1,11,16-18]}$ We compared the quantity of heat radiated towards the charge calculated from these values to that given by the more rigorous model of Gorog et al.[12] The expressions given by Manitius ${ }^{[1]}$

$$
\begin{aligned}
& E_{r_{g s}}=\varepsilon_{g} \varepsilon_{s} \\
& E_{r_{g w}}=\varepsilon_{g} \varepsilon_{w} \\
& E_{r_{w s}}=\varepsilon_{w} \varepsilon_{s}\left(1-\varepsilon_{g}\right)
\end{aligned}
$$

lead to the smallest difference (less than 5\%) and were therefore chosen in the present work.

The last radiation flux corresponds to the heat lost from the external surface of the kiln to the surrounding atmosphere. Considering a gray wall emitting into an infinite medium at a temperature $T_{a}$, gives

$$
\Phi_{r_{w a}}=A_{w_{o}} \varepsilon_{w_{o}} \sigma\left(T_{w_{o}}^{4}-T_{a}^{4}\right) \quad \text { with } \quad A_{w_{o}}=\pi d_{w_{o}}
$$

where the subscript $w_{o}$ designates the outer wall, which is generally heavily oxidized steel. The emissivity $\varepsilon_{w_{o}}$ is taken equal to 0.9 . 


\section{B. Convection}

Convective heat exchanges occur between the gas and the surfaces over which it flows, i.e. the uncovered kiln wall and the bed surface, but, because of the overriding importance of radiative heat transfer at high temperature, convection plays only a minor role in the present case.

The Reynolds number for the gas flow is greater than 40000, indicating a turbulent regime. The heat transfer coefficient $h_{c_{g w}}$ between the gas and the wall can therefore be calculated from the correlation ${ }^{[19]}$

$$
N u_{d_{w_{i}}}=\frac{h_{c_{g w}} d_{w_{i}}}{\lambda_{g}}=0.036 \operatorname{Re}_{d_{w_{i}}}^{0.8} \operatorname{Pr}^{0.33}\left(\frac{d_{w_{i}}}{Z}\right)^{0.055}
$$

which is valid in the turbulent regime when $10<Z / d_{w_{i}}<400$. Applied to the Carling kiln, this gives $h_{c_{g w}} \approx 10 \mathrm{~W} \mathrm{~m}^{-2} \mathrm{~K}^{-1}$. For the convective exchange between the gas and the bed surface, experience shows that $h_{c_{g s}}$ is probably greater than $h_{c_{g w}}$. Barr ${ }^{[13,14]}$ found a ratio of 1 to 2 between these two coefficients. The value taken in the present case was $h_{c_{g s}}=10 \mathrm{~W} \mathrm{~m}^{-2} \mathrm{~K}^{-1}$ and the influence of this parameter is shown in $\S \mathrm{VI} . \mathrm{A}$. The speed of rotation and the coal grain size do not seem to have a significant influence on convective heat transfer between the gas and the solid. ${ }^{[2,21]}$

Another convective heat exchange occurs at the outer kiln wall, which is cooled by natural convection in the surrounding air, or by forced convection when there is a wind. The correlations proposed by Ozisik ${ }^{[22]}$ gave a value of $h_{c_{w a}}=0.26 \mathrm{~W} \mathrm{~m}^{-2} \mathrm{~K}^{-1}$ for natural convection and $3 \leq h_{c_{w a}} \leq 40 \mathrm{~W} \mathrm{~m}^{-2} \mathrm{~K}^{-1}$ for forced convection with a transverse wind speed between 1 and $28 \mathrm{~m} \mathrm{~s}^{-1}$. A point value of $h_{c_{w a}}$ was also determined experimentally from temperature measurements on the Carling kiln, which gave 
$h_{c_{w a}}=17 \mathrm{~W} \mathrm{~m}^{-2} \mathrm{~K}^{-1}$, corresponding to a wind speed of $10.6 \mathrm{~m} \mathrm{~s}^{-1}$. We considered $h_{c_{w a}}$ as a given but uncertain parameter. Its influence on the results is shown in $\S$ VI.A.

The heat fluxes corresponding to these three exchange mechanisms can be expressed by

$$
\begin{gathered}
\Phi_{c_{g w}}=h_{c_{g w}} A_{w_{u}}\left(T_{g}-T_{w_{u}}\right) \\
\Phi_{c_{g s}}=h_{c_{g s}} A_{s}\left(T_{g}-T_{s}\right) \\
\Phi_{c_{w a}}=h_{c_{w a}} A_{w_{o}}\left(T_{w_{o}}-T_{a}\right)
\end{gathered}
$$

\section{Contact between the covered wall and the solid}

In the lower part of the bed, the movement of the grains is imposed by the kiln wall. Heat transfer therefore occurs essentially by conduction and radiation. Using an overall heat transfer coefficient between the covered wall and the solid $h_{c_{w s}}$, the heat flux transferred per unit length is given by

$$
\Phi_{c_{w s}}=h_{c_{w s}} A_{w_{c}}\left(T_{w_{c}}-T_{s}\right) \quad \text { with } \quad A_{w_{c}}=\frac{\alpha d_{w_{i}}}{2}
$$

Numerous models, based on the theory of heat penetration, lead to an equation of the type

$$
h_{c_{w s}}=\frac{2 \lambda_{e f f}}{\sqrt{\pi a_{e f f} \tau_{c_{w s}}}}
$$

where $\lambda_{\text {eff }}$ and $a_{\text {eff }}$ are respectively the effective thermal conductivity and diffusivity of the bed of grains and $\tau_{c_{w s}}$ is the contact time between the wall and the charge. This formula gives values that are high compared to the measurements and must be modified by introducing a contact resistance between the wall and the grains. ${ }^{[13]}$ Calculation of this resistance requires a knowledge of numerous parameters and the approach is 
difficult to apply in practice. Based on a dimensionless form of Eq. [19] together with available experimental results, Tsheng has established a new correlation ${ }^{[20]}$

$$
h_{c_{w s}}=11.6 \frac{\lambda_{e f f}}{A_{w_{c}}} G o^{0.3} \quad \text { with } \quad G o=\frac{\pi \omega \alpha d_{w_{i}}^{2}}{2 a_{e f f}}
$$

In all cases, calculation of $h_{c_{w s}}$ requires a knowledge of the effective conductivity of the charge, which in the present case is determined from the correlation of Zehner and Schlünder. ${ }^{[23]}$

\section{Heat transfer in the kiln wall}

Heat is transported through the wall by conduction. In order to obtain the fluxes exchanged on the inside with the gas and the solid and with the atmosphere on the outside, it is essential to calculate the temperature profile in the wall.

The wall of a pyrolysis furnace is composed of a thick layer of insulating material on the inside (20 cm of refractory concrete in the case of the Carling kiln) and a thin layer of conducting material on the outside $(2 \mathrm{~cm}$ of steel). The thermal resistance of the steel is about 300 times lower than that of the insulating layer, so that for the purposes of the calculation, only the refractory concrete need be considered. The thermophysical properties of the concrete were determined as follows: $\rho_{w}=2230 \mathrm{~kg}$ $\mathrm{m}^{-3}, c_{p_{w}}=1150 \mathrm{~J} \mathrm{~kg}^{-1} \mathrm{~K}^{-1}$ and $\lambda_{w}=1,6 \mathrm{~W} \mathrm{~m}^{-1} \mathrm{~K}^{-1}$, respectively by density measurements, by differential calorimetry and by the laser flash method..[2] These values vary little with temperature above $200^{\circ} \mathrm{C}$.

For a kiln operating in the steady state regime, the temperature profile within the wall is constant for an observer on the ground. However, for a reference point in the wall, the profile can be considered to be periodic, since a given point in the wall returns 
to the same temperature every revolution. It is the latter representation that is used for the present calculation. The temperature variation is considered in a sector of wall of volume $r \Delta r \Delta \varphi \Delta z$ in the transient regime and the calculation is continued until the periodic behavior is reached.

Figure 4 illustrates the shape of the temperature profile calculated in the wall at different angular positions for a charge temperature of $20^{\circ} \mathrm{C}$ and a gas temperature of $910^{\circ} \mathrm{C}$, corresponding to the values at the kiln entrance on the coal side. It is seen that only the first 15 millimeters of the wall are significantly affected by the temperature oscillations. It should also be noted that the temperature variations at the surface of the uncovered wall do not exceed $75^{\circ} \mathrm{C}$ and are small compared to $T_{g}-T_{w_{u}}$ and $T_{w_{u}}-T_{s}$. That is why the radiation flux from the wall to itself can be neglected in comparison with $\Phi_{r_{g w}}$ and $\Phi_{r_{w s}}$

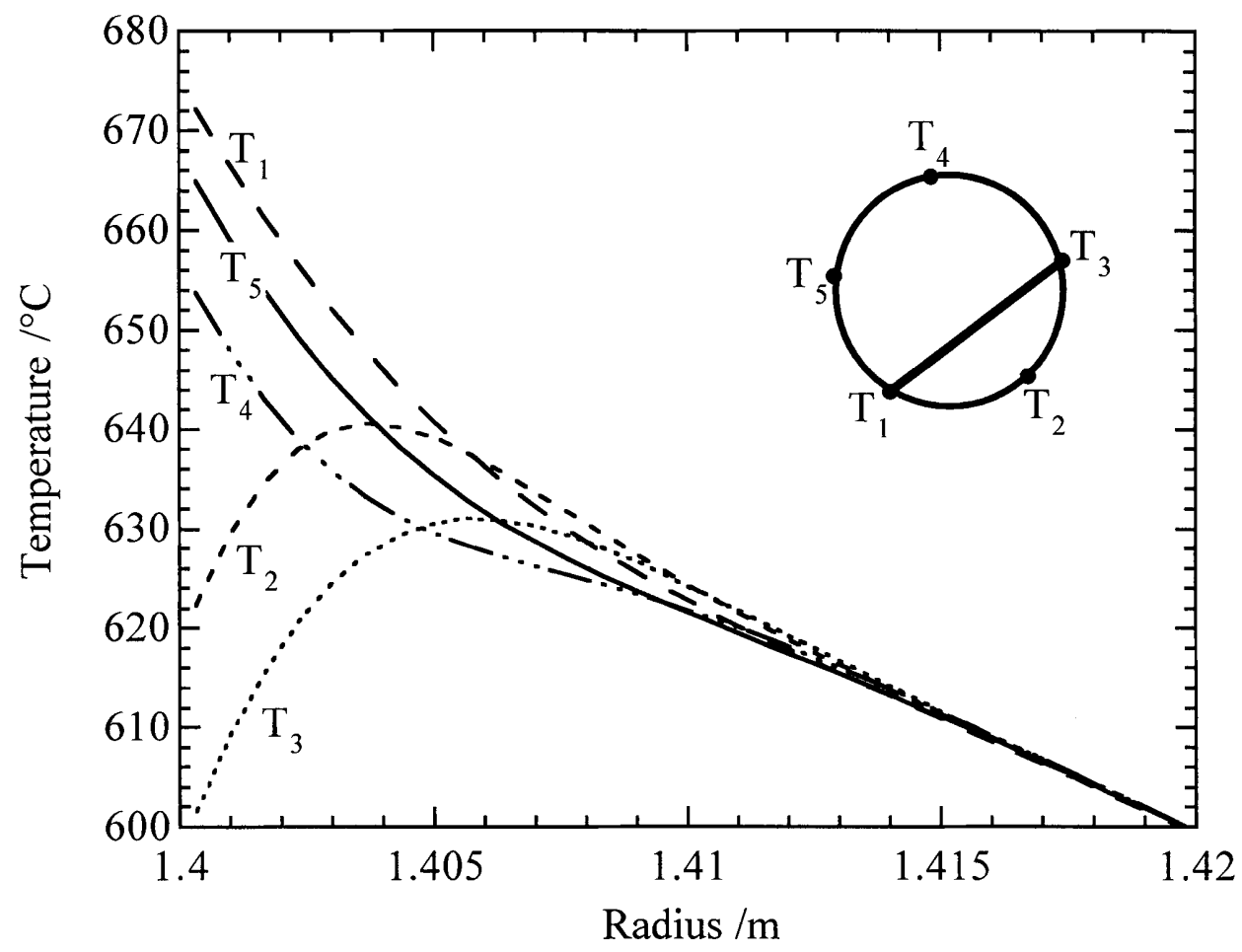

Fig. 4-Radial temperature profiles in the wall at various angular positions, at the coal end of the kiln. 


\section{COMBUSTION PHENOMENA}

The combustion phenomena that occur in the rotary kiln coal pyrolysis process merit a detailed study, since they represent the sole source of energy. They naturally include the combustion of the volatile species produced by pyrolysis of the coal, but also the combustion of the coke formed in the bed, together with that of the dust generated throughout the length of the furnace.

The volatile species are essentially of two types, namely those which condense at atmospheric temperature and pressure, designated as tars, and the light gases $\left(\mathrm{H}_{2}\right.$, $\mathrm{CH}_{4}, \mathrm{CO}, \mathrm{CO}_{2}$ and small quantities of light hydrocarbons). The tars can take part in the combustion phenomena either directly, or indirectly, after cracking to lighter molecules.

\section{A. Composition of the gas phase in the rotary kiln}

Analyses of the gas mixture were made at different points along the Carling kiln, together with measurements of the gas and charge temperatures, as explained in $\S$ VI.B. Figure 5 compares the measured gas compositions (a) to the gas evolution due to pyrolysis alone (b), calculated using the grain model ${ }^{[6]}$ by imposing the measured temperature profile, and leads to a number of interesting conclusions.

First of all, it is observed that the methane evolution peak occurs at $z=28 \mathrm{~m}$, while that for hydrogen is situated at $z=39 \mathrm{~m}$. The complete absence of hydrogen and methane in the gas samples taken at 30,37 and $44 \mathrm{~m}$ show that the combustion of these two species must be very rapid. The assumption of an instantaneous combustion of these two gases in this zone of the furnace therefore appears quite realistic. The presence of a large quantity of hydrogen at $z=10 \mathrm{~m}$ can only be explained by cracking of the tars, since hydrogen evolution between 10 and $30 \mathrm{~m}$ is very weak. 

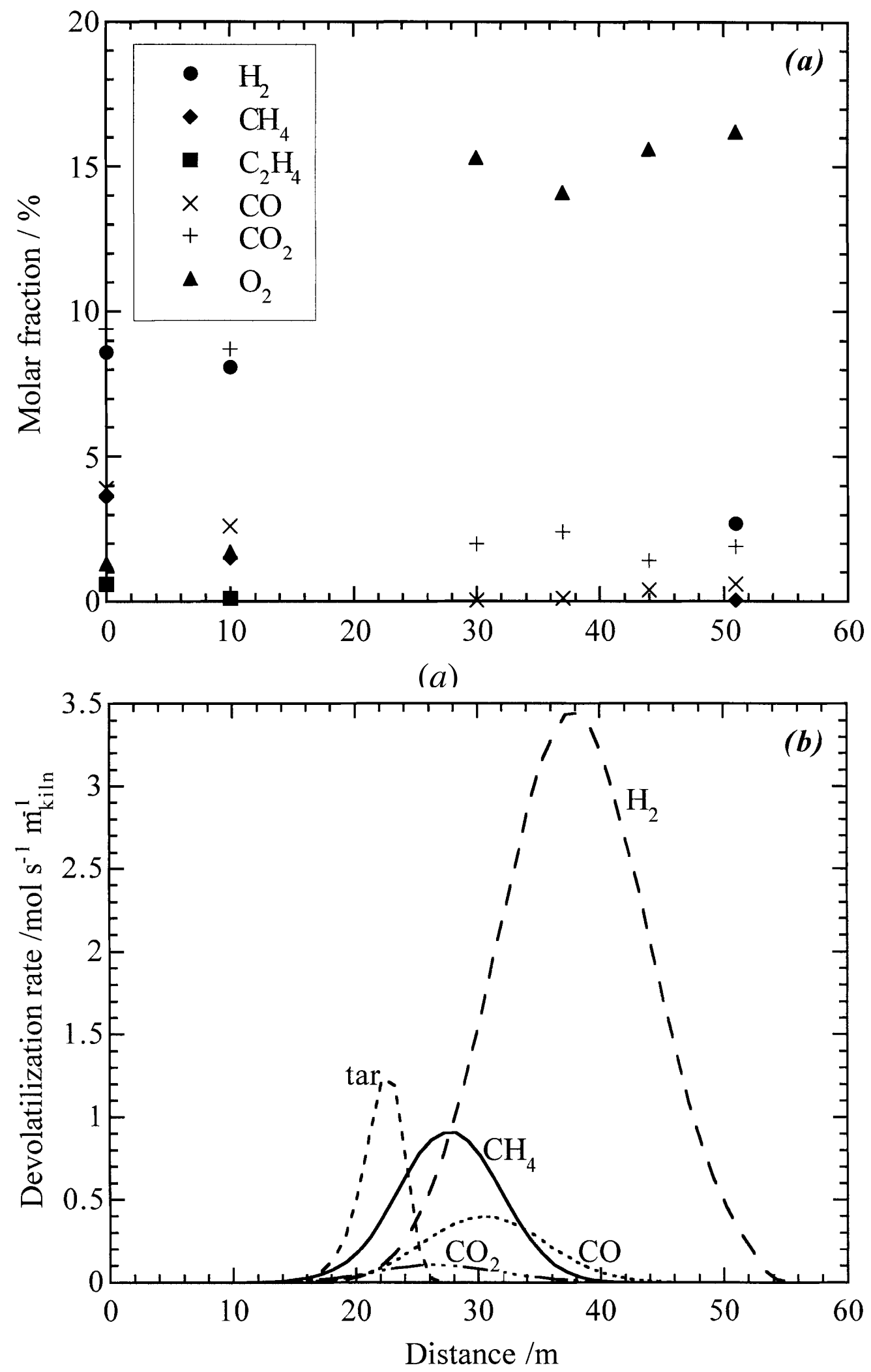

(b)

Fig. 5-Axial gas composition profiles: (a) measured molar fractions and (b) molar devolatilization rates calculated from the grain model. 
Similarly, the increase in the quantity of methane over the first 10 meters of the kiln is also an indication of cracking of the tars in this zone. Furthermore, the very low oxygen content at $z=10 \mathrm{~m}$ shows that the combustion of tars and cracking products occurs with a deficiency of oxygen. Modeling of the combustion in this region of the furnace requires several investigations, including determination of the tar cracking kinetics, the nature and quantity of the cracking products and their combustion kinetics.

\section{B. Cracking and combustion of the tars}

The nature of the products formed by cracking of the tars was studied as a function of the temperature and residence time. ${ }^{[25-30]}$ The degree of cracking increases with both temperature and residence time. The quantity of carbon (soot) formed during cracking increases with temperature and attain $21 \%$ of the tar by weight ${ }^{[26]}$ in conditions similar to those prevailing in the Carling kiln. The quantity of $\mathrm{C}_{2}$ and $\mathrm{C}_{3}$ hydrocarbons produced reaches a maximum at about $750^{\circ} \mathrm{C}$, but extensive cracking of the tars leads essentially to a mixture of hydrogen, methane and carbon monoxide (typically $60 \% \mathrm{H}_{2}$, $\left.20 \% \mathrm{CH}_{4}, 20 \% \mathrm{CO}\right) .{ }^{[26]}$ Lahouste is the only investigator to have studied the influence of the presence of oxygen. He found that for $\mathrm{O}_{2}$ concentrations less than $10 \%$, there was no significant difference in the cracking products and that tar combustion occurred only beyond $15 \%$ of oxygen in the gas. ${ }^{[25]}$ As regards the kinetics of cracking, Serio proposes a first order kinetic law. ${ }^{[28]}$

Both gaseous and solid cracking products can burn and compete to consume the little available oxygen. However, we assumed that soot remains inert. This simplification is justified by the fastest gas combustion and from the observation of a large unburnt carbon layer deposited on the furnace wall in this zone. 


\section{Combustion of the light gases}

The present section considers the combustion of the light gases produced by pyrolysis and cracking of the tars in the zone between $z=10$ and $z=30 \mathrm{~m}$, where it occurs with an oxygen deficiency. Combustion can be considered to take place almost instantaneously in the remainder of the kiln. Combustion in the gas phase involves radical mechanisms, with a large number of reactions and intermediate products (up to 835 reactions and 42 intermediate products for the combustion of methane $\left.{ }^{[31]}\right)$. For obvious reasons of computing time, these mechanisms cannot therefore be rigorously described in the overall rotary kiln model.

In order to evaluate the kinetics of the combustion of volatile species in the rotary kiln, we carried out calculations using the experimental gas temperature profile in the Carling kiln, together with the fluxes of volatile species given by the grain model, Serio's tar cracking kinetics, ${ }^{[28]}$ and the cracking matter balance of Hesp and Waters, ${ }^{[26]}$ assuming the absence of soot and tar combustion. ${ }^{[25]}$ Three combustion reactions were considered:

$$
\begin{gathered}
\mathrm{CH}_{4}+2 \mathrm{O}_{2} \rightarrow \mathrm{CO}_{2}+2 \mathrm{H}_{2} \mathrm{O} \\
\mathrm{H}_{2}+\frac{1}{2} \mathrm{O}_{2} \rightarrow \mathrm{H}_{2} \mathrm{O} \\
\mathrm{CO}+\frac{1}{2} \mathrm{O}_{2} \rightarrow \mathrm{CO}_{2}
\end{gathered}
$$

for which the rate constants and activation energies are determined by preliminary calculations using Chemkin's software. ${ }^{[32]}$ These calculations, which are described in detail elsewhere, ${ }^{[24]}$ reveal that the cracking of tars and the combustion of light gases can be considered to be instantaneous in a rotary kiln, but that only a fraction of the hydrogen, methane and carbon monoxide can burn before exhaustion of the oxygen. 


\section{Combustion of the coke}

The gas analyses in Figure 5a show the presence of $\mathrm{CO}$ and $\mathrm{CO}_{2}$ at $z=44$ and $z$ $=51 \mathrm{~m}$. This proves that combustion of the coke takes place in this zone of the furnace, since there is no evolution of $\mathrm{CH}_{4}, \mathrm{CO}$ or $\mathrm{CO}_{2}$ from pyrolysis at this location. Based on the known coal and fume flow rates, a molar concentration of $2 \%$ of $\mathrm{CO}_{2}$ at $z=30 \mathrm{~m}$ corresponds to consumption of $3 \%$ of the charge in the last 26 meters of the kiln. Confirmation of combustion of the coke in the bed is given by the temperature profiles measured in the charge and in the gas (§VI.B. Figure 7), since the increase in temperature of the solid beyond the point where the temperature curves cross indicates the presence of a heat source within the charge.

In the present rotary kiln model, it is assumed that combustion of the coke is limited to the reaction

$$
\mathrm{C}+\mathrm{O}_{2} \rightarrow \mathrm{CO}_{2}
$$

and, like Essenhigh, ${ }^{[33]}$ the combustion rate is calculated by considering 3 resistances to matter transfer in series, corresponding respectively to adsorption, desorption and external transfer:

$$
v_{c o m b}=\left(v_{a d s}^{-1}+v_{d e s}^{-1}+v_{s}^{-1}\right)^{-1}
$$

with

$$
\begin{gathered}
v_{a d s}=k_{0 a d s} \exp \left(-\frac{E_{a d s}}{\mathrm{R} T_{s}}\right) p_{\mathrm{O}_{2}} \\
v_{d e s}=k_{0 d e s} \exp \left(-\frac{E_{d e s}}{\mathrm{R} T_{s}}\right) \\
v_{s}=\frac{6}{d_{g r}} \kappa_{s} k_{s} c_{\mathrm{O}_{2}}
\end{gathered}
$$


The external mass transfer coefficient reflects the exchange of matter between the gas and the external surface of a grain at the surface of the bed. In the lack of a suitable correlation, it is calculated by correcting the value $k_{s}$ obtained for an isolated sphere in a gas stream ${ }^{[34]}$ by a factor $\kappa_{s}$ taken equal to 0.55 . At low temperature, below $1000 \mathrm{~K}$, the combustion occurs in the chemical regime and is controlled by the rate of desorption. At higher temperatures, external transfer becomes the rate limiting factor.

Combustion of the coke grains is simulated by a source term in the grain model. At low temperature, the combustion rate varies as a function of the radius and is determined by the temperature at the point considered. At high temperatures, the combustion rate is identical throughout the grain and is determined by the rate of external transfer of oxygen.

\section{E. Combustion of dust}

The combustion of coal and coke dust particles certainly contributes to the supply of energy in the rotary kiln. However, in order to describe it, in addition to a combustion model, it is necessary to be able to predict the quantity of dust generated at each point in the bed. An empirical correlation of this sort exists in the case of a petroleum coke calcination furnace. ${ }^{[35]}$ Nevertheless, in the lack of experimental data concerning the generation of dust in a rotary coal pyrolysis kiln, this phenomenon will be ignored. 


\section{THE MATHEMATICAL MODEL}

\section{A. Principle}

Our mathematical model is based on the description of the process given above and simulates the following physicochemical and thermal phenomena in the steady state regime:

- the flow of solid, which is axially of the piston type, with each grain undergoing successive periods of rolling down the inclined bed surface and rotation with the bulk of the bed imposed by its contact with the kiln wall;

- the flow of gas, of the piston type as well;

- the heat transfer mechanisms, including axial convection of the solid, axial convection of the gas, radial conduction in the kiln wall, radial conduction within the grains, and numerous radiant and convective exchanges within a given kiln cross section;

- drying, pyrolysis (with separate evolution of the volatile gases), combustion and extinction of the grains;

- cracking of the tars and combustion of the volatile species.

Numerical solution of the equations requires their discretization as a function of $z$. Slices of equal length $\Delta z$ are used to this effect. In each slice, the temperature and gas composition are assumed to be uniform. In contrast, the temperature of the kiln wall varies with $r$ and $\varphi$. Finally, the charge, a collection of grains whose behavior varies depending on whether they are on the bed surface, in contact with the wall or in the middle of the bed, is described with the aid of a single reference grain (cf. §V.B). 
The calculation begins at the coal end. The temperature and composition of the charge are known, but it is necessary to estimate the flowrate, composition and temperature of the fumes. In the remainder of the furnace, the solid, gas and wall temperatures, together with the composition of each phase, are calculated successively for each slice of the kiln. If the initialization for the fumes is correct, the composition and temperature of the gas calculated on the coke side should correspond to the air injected into the furnace. If not, the temperature and composition of the fumes at the coal end are modified and the calculation is repeated. A few iterations are sufficient.

\section{$B$. The reference grain hypothesis}

In its movement within the charge, a grain passes successively into the active surface zone then against the kiln wall or inside the bed. Each grain thus has its own thermal history, which depends on the different trajectories followed in the bed. However, because of the stirring in the active surface layer, on average, all the grains follow a similar overall path. The mean residence times at the surface $\tau_{s}$ and in contact with the walls $\tau_{w}$ are thus identical for each grain. The mean residence time at the center of the charge is then $\tau-\tau_{s}-\tau_{w}$.

The method chosen to describe simply the complex behavior of the charge consists in following the movement of a "reference grain", reflecting the whole of the charge, whose mean path is characterized by the ratios $\tau_{s} / \tau$ and $\tau_{w} / \tau$. The value of the first of these ratios is given by Eq. [5], while that of the second can be calculated in a similar manner, assuming that there is no accumulation of matter in any cross section of the furnace:

$$
\frac{\tau_{w}}{\tau}=\frac{4 C_{\varepsilon} \alpha}{\alpha-\sin \alpha} \frac{d_{g r}}{d_{w_{i}}}
$$


Calculation in the nominal conditions of the Carling rotary kiln shows that, on the coal side, a grain comes to the bed surface on average every $14 \mathrm{~cm}$ and comes in contact with the furnace wall every $3 \mathrm{~m}$. A value of $\Delta z=14 \mathrm{~cm}$ was therefore taken so that the reference grain comes to the bed surface in each slice. In these conditions, the grain should come in contact with the wall in only one out of every 21 slices and would no longer be representative of the whole of the charge. The solution retained was therefore to consider that the reference grain comes in contact with the wall in each slice but on each occasion receives only $1 / 21^{\text {st }}$ of the heat flux given up by the wall. This fraction corresponds to the probability $p$ that a grain will come in contact with the wall in a given slice. It is also the ratio between the flowrate of grains in contact with the wall in the slice and the total flowrate: ${ }^{[10]}$

$$
p=\frac{\omega d_{w_{i}} \Delta z}{2 C_{\varepsilon}^{2} d_{g r}^{2} \Phi_{n, g r}}
$$

where $\Phi_{n, g r}$ is the grain flowrate, expressed as the number of grains per unit time.

\section{Calculation procedure}

After having initialized the different variables, the charge profile, the filling angle and the axial velocity are calculated for each value of $z$ using Eqs [1] to [3]. The calculation continues slice by slice. For each slice, the mean residence time is first of all determined

$$
\tau=\frac{\Delta z}{u(z)}
$$

together with the time spent at the bed surface $\tau_{s}$ (Eq. [5]) and in contact with the wall $\tau_{w}$ (Eq. [29]). The procedure is then as follows. 


\section{i) Grain at the bed surface}

The equations of the grain model are solved during the time $\tau_{s}$ by considering the reference grain to be on the bed surface. The boundary conditions necessary for this calculation are the solid temperature in the previous slice, which is known, the gas temperature in the slice concerned, known from the gas heat balance in the previous slice, and the temperature of the uncovered wall, which is unknown at this point in the calculation. It is given an estimated value which is modified at a later stage.

The heat fluxes $\Phi_{r_{g s}}, \Phi_{r_{w s}}$ and $\Phi_{c_{g s}}$ received by the grain from the gas and the wall are given by Equations [9], [11] and [16]. In order to allow for the fact that the grain model considers the surface area of the grain to be $\pi d_{g r}^{2}$ wheareas the apparent area of the bed surface occupied by a grain is $\left(C_{\varepsilon} d_{g r}\right)^{2}$, the heat exchange coefficients used in the grain model are corrected in proportion.

\section{ii) Grain in contact with the wall}

The next stage considers the reference grain to be in contact with the kiln wall. During the time $\tau_{p}$, the equations of the grain model are solved, together with the conduction equation in the different sectors of the wall covered by the charge, allowing for heat losses from the external surface $\Phi_{r_{w a}}$ and $\Phi_{c_{w a}}$ (Eqs. [13] and [17]). In contact with the wall, the heat flux received by the grain takes into account both the probability of it coming into contact with the wall (Eq. [30]) and the ratio of the surface areas. Thus, for the grain model, the heat transfer coefficient used is

$$
h_{w-g r}=\frac{p C_{\varepsilon}^{2}}{\pi} h_{c_{w s}}
$$




\section{iii) End of the calculation in the wall}

The radial temperature profile in each portion of the uncovered wall is calculated by considering conduction and the heat fluxes either received from the gas $\Phi_{r_{g w}}$ and $\Phi_{c_{g w}}$ or given up to the solid $\Phi_{r_{w s}}$ by the inside face, and those lost by the outside face $\Phi_{r_{w a}}$ and $\Phi_{c_{w a}}$.

The steps $i$ ) to iii) are then repeated, using the modified kiln wall temperature. The new temperature profile in the wall is compared to the previous one. If the difference in temperature is less than a limiting value $\Delta T_{p \text {,lim }}$, fixed at $0.05 \mathrm{~K}$, the calculation moves on to step iv), if not, steps i) to iii) are repeated.

\section{iv) Grain inside the bed}

The grain model calculation then considers, for a time $\tau-\tau_{s}-\tau_{w}$, the reference grain to be inside the bed, where it is assumed that no heat is exchanged with the other grains. This hypothesis is justified by the small depth of penetration of the heat in the charge, in contact with either the wall $(11 \mathrm{~mm})$ or the gas $(4 \mathrm{~mm}) \cdot{ }^{[10]}$ It can therefore be estimated that only a single layer of grains is affected by the presence of the wall or the gas.

\section{v) Matter balance in the gas}

The calculations performed in the grain model give the fluxes of volatile species evolved in each slice, together with the flux of $\mathrm{CO}_{2}$ produced by combustion of the coke in the bed. Matter balances in the gas, taking into account these inputs from the solid, together with combustion of the light gases and cracking of the tars, determine the composition of the gas at the slice exit. 
It is assumed that nitrogen remains inert in the kiln and that the cracking and combustion reactions are instantaneous. As indicated in $\S \mathrm{IV}$, it is considered that the tars are completely cracked, producing 20 wt. $\%$ of soot and $80 \%$ of mixed gases. This gas mixture is composed of $60 \% \mathrm{H}_{2}, 20 \% \mathrm{CH}_{4}$ and $20 \% \mathrm{CO}$ in moles. ${ }^{[26]}$ The combustion of soot is neglected and that of the gaseous cracking products is incomplete due to the lack of oxygen. Calculation has shown that $57 \%$ of the methane, $34 \%$ of the hydrogen and $36 \%$ of the carbon monoxide are consumed during normal operation of the Carling kiln. ${ }^{[24]}$ In the general case, the corresponding degrees of combustion are designated by $f_{\mathrm{CH}_{4}}, f_{\mathrm{H}_{2}}$ and $f_{\mathrm{CO}}$.

The molar flux of the species $i\left(i=\operatorname{tar}, \mathrm{CH}_{4}, \mathrm{H}_{2}, \mathrm{CO}_{2}, \mathrm{CO}\right.$ or $\left.\mathrm{H}_{2} \mathrm{O}\right)$ evolved in the furnace slice considered is designated by $\Phi_{d e v, i}^{*}$, while $\Phi_{c r a, i}^{*}\left(i=\mathrm{CH}_{4}, \mathrm{H}_{2}\right.$ or $\left.\mathrm{CO}\right)$ represents the molar fluxes produced by cracking of the tars, and $\Phi_{c o m b, i}^{*}\left(i=\mathrm{CH}_{4}, \mathrm{H}_{2}\right.$ or $\mathrm{CO}$ ) represents the fluxes consumed by each of the three combustion reactions (Eqs. [21] to [23]). The mean molecular weight of the cracking gas $M_{g, c r a}$ is taken equal to 10 $\mathrm{g} \mathrm{mol}^{-1}$ and that of the tars $M_{\text {tar }}$ equal to $228 \mathrm{~g} \mathrm{~mol}^{-1}\left(\mathrm{C}_{18} \mathrm{H}_{12}\right)$. This gives

$$
\begin{gathered}
\Phi_{c r a, \mathrm{H}_{2}}^{*}=0.6 \times 0.8 \frac{M_{t a r}}{M_{g, c r a}} \Phi_{d e v, t a r}^{*} \\
\Phi_{c r a, \mathrm{CO}}^{*}=\Phi_{c r a, \mathrm{CH}_{4}}^{*}=0.2 \times 0.8 \frac{M_{t a r}}{M_{g, c r a}} \Phi_{d e v, t a r}^{*} \\
\Phi_{c o m b, \mathrm{CH} 4}^{*}=\Phi_{d e v, \mathrm{CH}_{4}}^{*}+f_{\mathrm{CH}_{4}} \Phi_{c r a, \mathrm{CH}_{4}}^{*} \\
\Phi_{c o m b, \mathrm{H}_{2}}^{*}=\Phi_{d e v, \mathrm{H}_{2}}^{*}+f_{\mathrm{H}_{2}} \Phi_{c r a, \mathrm{H}_{2}}^{*} \\
\Phi_{c o m b, \mathrm{CO}}^{*}=\Phi_{d e v, \mathrm{CO}}^{*}+f_{\mathrm{CO}} \Phi_{c r a, \mathrm{CO}}^{*}
\end{gathered}
$$


If $\Phi_{c o m b, \mathrm{CO}_{2}}^{*}$ is the molar flux of carbon dioxide produced by combustion of the coke, $\Phi_{i}^{*}(z)$ is the molar flux of $i$ leaving the slice and $\Phi_{i}^{*}(z+\Delta z)$ is that entering it, the matter balances for the gas are

$$
\begin{gathered}
\Phi_{\mathrm{N}_{2}}^{*}(z+\Delta z)=\Phi_{\mathrm{N}_{2}}^{*}(z) \\
\Phi_{\mathrm{CH}_{4}}^{*}(z+\Delta z)=\Phi_{\mathrm{CH}_{4}}^{*}(z)-\Phi_{d e v, \mathrm{CH}_{4}}^{*}-\Phi_{c r a, \mathrm{CH}_{4}}^{*}+\Phi_{c o m b, \mathrm{CH}_{4}}^{*} \\
\Phi_{\mathrm{H}_{2}}^{*}(z+\Delta z)=\Phi_{\mathrm{H}_{2}}^{*}(z)-\Phi_{d e v, \mathrm{H}_{2}}^{*}-\Phi_{c r a, \mathrm{H}_{2}}^{*}+\Phi_{c o m b, \mathrm{H}_{2}}^{*} \\
\Phi_{\mathrm{CO}}^{*}(z+\Delta z)=\Phi_{\mathrm{CO}}^{*}(z)-\Phi_{d e v, \mathrm{CO}}^{*}-\Phi_{c r a, \mathrm{CO}}^{*}+\Phi_{c o m b, \mathrm{CO}}^{*} \\
\Phi_{\mathrm{CO}_{2}}^{*}(z+\Delta z)=\Phi_{\mathrm{CO}_{2}}^{*}(z)-\Phi_{d e v, \mathrm{CO}_{2}}^{*}-\Phi_{c o m b, \mathrm{CO}_{2}}^{*}-\Phi_{c o m b, \mathrm{CH}_{4}}^{*}-\Phi_{c o m b, \mathrm{CO}}^{*} \\
\Phi_{\mathrm{H}_{2} \mathrm{O}}^{*}(z+\Delta z)=\Phi_{\mathrm{H}_{2} \mathrm{O}}^{*}(z)-\Phi_{d e v, \mathrm{H}_{2} \mathrm{O}}^{*}-2 \Phi_{c o m b, \mathrm{CH}_{4}}^{*}-\Phi_{c o m b, \mathrm{H}_{2}}^{*} \\
\Phi_{\mathrm{O}_{2}}^{*}(z+\Delta z)=\Phi_{\mathrm{O}_{2}}^{*}(z)+\Phi_{c o m b, \mathrm{CO}_{2}}^{*}+2 \Phi_{c o m b, \mathrm{CH}_{4}}^{*}+\frac{1}{2} \Phi_{c o m b, \mathrm{H}_{2}}^{*}+\frac{1}{2} \Phi_{c o m b, \mathrm{CO}}^{*}
\end{gathered}
$$

It should be noted here that, if devolatilization is assumed complete, these balances can also be expressed and solved globally between the entrance and exit of the kiln. It is then possible to calculate the composition of the fumes at the coal end as a function of the air flowrate and to determine the coefficients $f_{i}$ which satisfy the overall balance. This type of calculation is performed at the beginning of the program to determine the $f_{i}$ values and initialize the composition of the gas.

\section{vi) Heat balance for the gas}

The heat balance for the gas, which is useful for calculating its temperature, must take account of exchanges with the walls, convective transport, the production and heating of volatile species, and the cracking and combustion reactions. The enthalpy of cracking of the tars is denoted $\Delta_{r} H_{c r a}$, while the enthalpy of combustion of the species $i$ is designated $\Delta_{r} H_{i}$, and $c_{p_{i}}^{*}$ is the molar specific heat of the constituent $i$. Since the 
variation in temperature between two successive slices never exceeds $5 \mathrm{~K}$, it is assumed that the molar specific heats vary little between $z$ and $z+\Delta z$. The heat balance for the gas can therefore be written

$$
\begin{array}{r}
{\left[\sum_{i} c_{p_{i}}^{*} \Phi_{i}^{*}(z+\Delta z)\right]\left[T_{g}(z+\Delta z)-T_{g}(z)\right]=\left[\sum_{i} c_{p_{i}}^{*} \Phi_{d e v, j}^{*}\right]\left[T_{g}(z)-T_{s}(z)\right]} \\
+\left(\Phi_{r_{g w}}+\Phi_{r_{g s}}+\Phi_{c_{g s}}+\Phi_{c_{g w}}\right) \Delta z+\Phi_{d e v, t a r}^{*} \Delta_{r} H_{c r a} \\
+\Phi_{c o m b, \mathrm{CH}_{4}}^{*} \Delta_{r} H_{\mathrm{CH}_{4}}+\Phi_{c o m b, \mathrm{H}_{2}}^{*} \Delta_{r} H_{\mathrm{H}_{2}}+\Phi_{c o m b, \mathrm{CO}}^{*} \Delta_{r} H_{\mathrm{CO}}
\end{array}
$$

and enables calculation of $T_{g}(z+\Delta z)$.

\section{vii) Case of extinction}

Over a length $Z_{\text {ext }}$ of several meters at the coke end, a volume flux of water $\Phi_{V, \text { ext }}$ is sprayed uniformly on the surface of the charge in order to stop the incipient combustion of the coke. The extinction process is described by assuming that all the water is vaporized and that the energy necessary for vaporization is supplied exclusively by the solid present on the bed surface. In the model, a source term

$$
\Phi_{e x t, \mathrm{H}_{2} \mathrm{O}}^{*}=\frac{\Phi_{V, e x t} \rho_{\mathrm{H}_{2} \mathrm{O}} \Delta z}{M_{\mathrm{H}_{2} \mathrm{O}} Z_{\text {ext }}}
$$

is therefore added in the water vapor matter balance (Eq. [43]) and, from a thermal standpoint, the heat energy $\Phi_{e x t, \mathrm{H}_{2} \mathrm{O}}^{*} \Delta_{v} H_{\mathrm{H}_{2} \mathrm{O}}$ is distributed in the form of a negative source term in the grain model.

\section{RESULTS}

The present section describes the principal results obtained using the model. A stepwise procedure was followed. First of all, the sensitivity of the model to the discretization parameters and certain thermal parameters was evaluated. The model was 
then validated by comparison with measurements made specially on the industrial kiln, before using it for process simulation and optimization.

\section{A. Study of the sensitivity}

The influence of purely numerical parameters, such as the length of the kiln slices $\Delta z$, the number of angular sectors $n_{q}$, the number of radial mesh cells in the wall $n_{r}$, the limiting value $\Delta T_{p, \text { lim }}$ for the difference in wall temperature between two iterations, the number of nodes in the grain $n_{g r}$, and the time increment $\Delta t$ in the grain model, must be examined to determine their optimum values. These optimum values are those that minimize the computing time without influencing the results. Based on the calculations performed, ${ }^{[24]}$ the values chosen were $\Delta z=14 \mathrm{~cm}, n_{\varphi}=250, n_{r}=200, \Delta T_{p, \text { lim }}$ $=0.05 \mathrm{~K}, n_{g r}=200$, and $\Delta t=2 \mathrm{~ms}$.

Table I. Influence of Thermal Parameters

\begin{tabular}{|c|c|c|}
\hline Parameter & Value & $\begin{array}{l}\text { Maximum Solid } \\
\text { Temperature, }{ }^{\circ} \mathrm{C}\end{array}$ \\
\hline \multirow{3}{*}{$\varepsilon_{g r}$} & 0.8 & 921 \\
\hline & 0.9 & 916 \\
\hline & 1 & 903 \\
\hline \multirow[t]{3}{*}{$\varepsilon_{w}$} & 0.8 & 921 \\
\hline & 0.9 & 925 \\
\hline & 1 & 922 \\
\hline \multirow[t]{3}{*}{$\varepsilon_{\text {dust }}$} & 0 & 875 \\
\hline & 0.05 & 921 \\
\hline & 0.1 & 931 \\
\hline \multirow{3}{*}{ 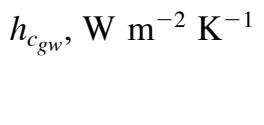 } & 3 & 921 \\
\hline & 10 & 921 \\
\hline & 30 & 896 \\
\hline \multirow[t]{3}{*}{$h_{c g s}, \mathrm{~W} \mathrm{~m} \mathrm{~m}^{-2} \mathrm{~K}^{-1}$} & 3 & 921 \\
\hline & 10 & 921 \\
\hline & 30 & 874 \\
\hline \multirow{3}{*}{ 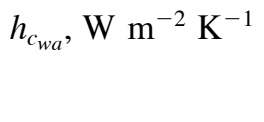 } & 1 & 872 \\
\hline & 17 & 921 \\
\hline & 30 & 937 \\
\hline \multirow[t]{3}{*}{$\Delta_{r} H_{\text {pyro }}, \mathrm{kJ} \mathrm{kg}^{-1}$} & 100 & 747 \\
\hline & 300 & 921 \\
\hline & 600 & 1090 \\
\hline \multirow[t]{3}{*}{$\Delta_{r} H_{\mathrm{cra}}, \mathrm{kJ} \mathrm{kg}^{-1}$} & 2200 & 648 \\
\hline & 2400 & 956 \\
\hline & 2600 & 1070 \\
\hline
\end{tabular}


Among the numerous parameters in the model, some of the thermal parameters are known with a relatively low accuracy, either because they were taken from the literature, or because they could not be measured exactly. Table 1 shows the influence of $\varepsilon_{g r}, \varepsilon_{w}, \varepsilon_{d u s t}, h_{c_{g w}}, h_{c_{g s}}, h_{c_{w a}}, \Delta_{r} H_{p y r o}$, and $\Delta_{r} H_{c r a}$ on the maximum temperature attained by the charge. The model is particularly sensitive to the enthalpies of the pyrolysis reactions $\Delta_{r} H_{\text {pyro }}$ and those for cracking of the tars $\Delta_{r} H_{c r a}$. These parameters should therefore be precisely evaluated. For pyrolysis, the value of $300 \mathrm{~kJ} \mathrm{~kg}^{-1}$ was considered to be reasonable in the light of the literature survey ${ }^{[6]}$ In contrast, no data were available concerning the enthalpy of cracking of the tars, and the value of $2400 \mathrm{~kJ} \mathrm{~mol}^{-1}$ was determined by the need to satisfy the overall heat balance for the gas.

\section{B. Validation of the model}

Validation of the model requires precise data concerning the operation of an industrial kiln. The routine on-line temperature measurements give only indicative values used to control the furnace, but are not suitable for validation purposes. We therefore undertook specific measurement campaigns on the Carling kiln, in collaboration with the Centre de Pyrolyse at Marienau.

Six holes, drilled through the kiln wall at different distances along the furnace axis, were used to precisely measure the temperature and take solid and gas samples (Figure 6). The temperature of the charge was measured using a 1-mm diameter type $\mathrm{K}$ sheathed thermocouple inserted through the holes, without the need to stop the furnace. The gas temperature was determined using a suction thermocouple in order to prevent errors due to extraneous radiation. A 2 minute stoppage was necessary to introduce the thermocouple and obtain a stable value of $T_{g}$. Solid samples were removed directly 
through the holes and immediately quenched in water. Finally, gas samples were taken with the aid of a water-cooled tube and stored in glass bulbs. Apart from the holes, measurements were also made at other points, particularly at the two ends of the kiln.

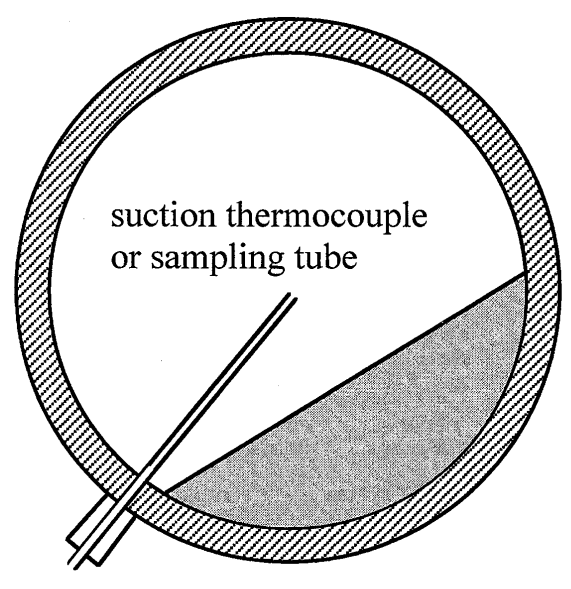

Position of the hole for measuring the gas temperature or for sampling gas

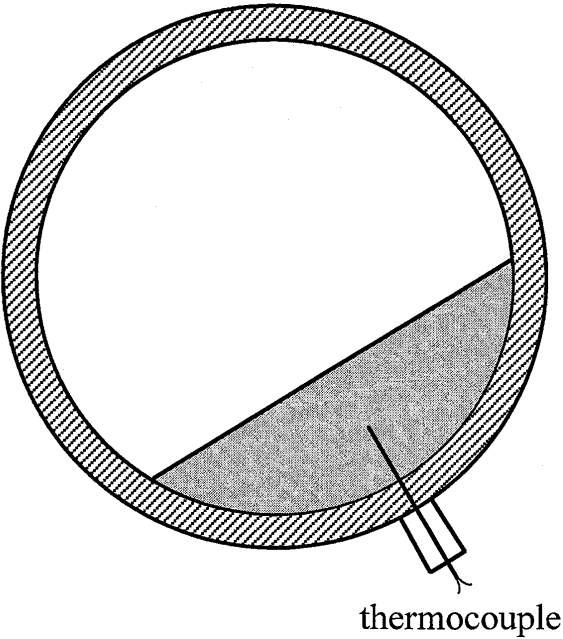

Position of the hole for measuring the solid temperature

Fig. 6-Temperature measurements and gas sampling.

Figure 7 shows the good agreement between the measured and calculated temperature profiles in the charge and the gas. Due to obstruction of the second hole by graphite deposition (at $z=20 \mathrm{~m}$, in the tar cracking zone), the gas temperature and composition could not be measured at this point.

Because the pyrolysis is controlled by heat transfer, the degree of conversion of the coal depends on the temperature attained in the solid. Since the temperature profile in the charge is correctly represented, the same is true for the conversion profile (Figure 8).

As regards the composition of the gas, the molar fluxes calculated by the model agree with those determined from the analyses of the gas samples (Figure 9). However, two abnormal points can be seen. Thus, the oxygen flux measured at $z=30 \mathrm{~m}$ is not in 
agreement, either with the calculation or with the other experimental values, while the hydrogen and carbon dioxide fluxes measured at $z=51 \mathrm{~m}$ are excessively high. The latter points are probably due to a sample taken too close to the bed surface, since in this case the tube was inserted through a door situated beneath the heating hood.

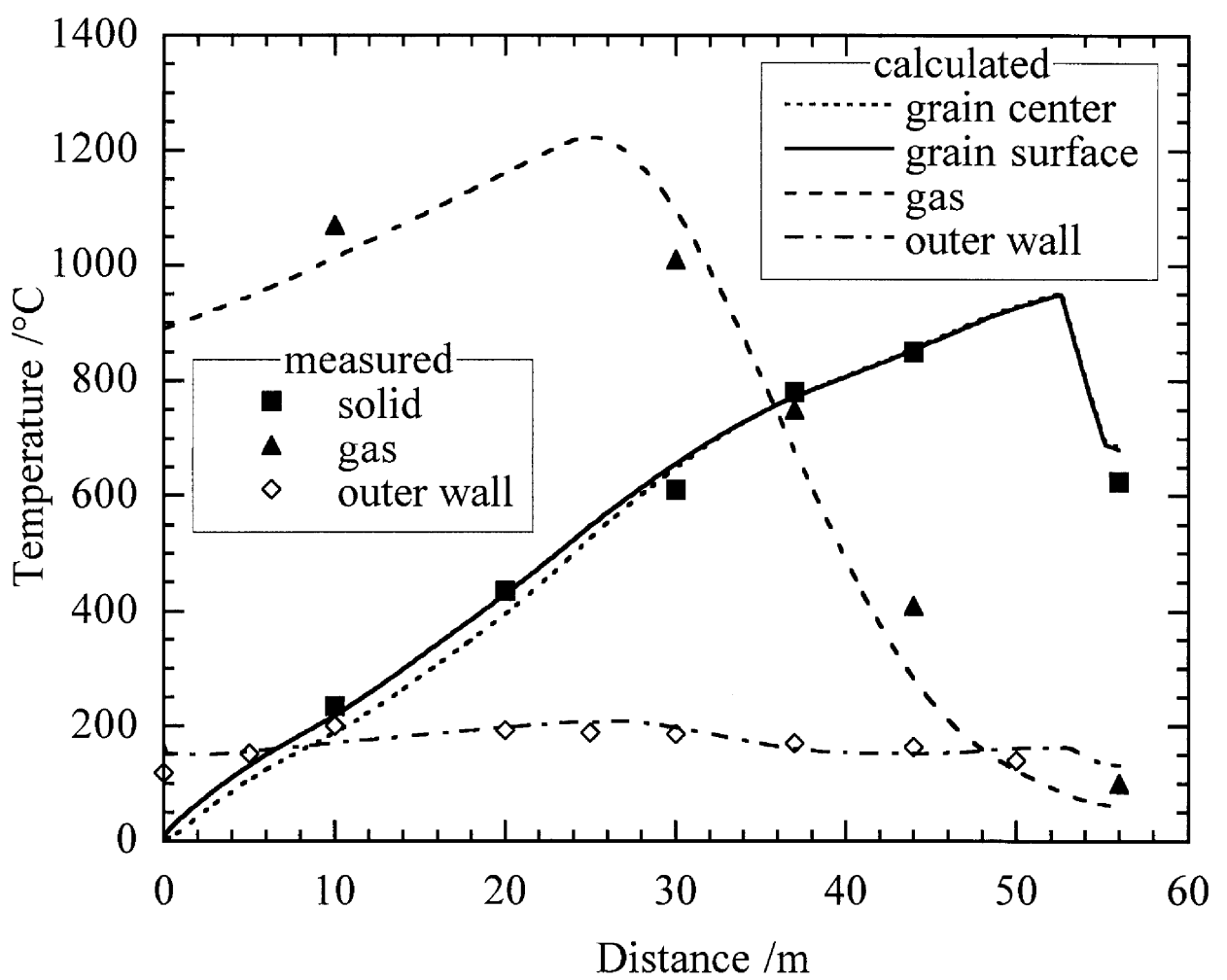

Fig. 7 -Comparison of measured and calculated axial temperature profiles.

However, it should be emphasized that, even though imperfect, the measurements made on an industrial plant improved understanding of the process and provided a coherent set of data sufficient to validate the model.

\section{Application of the model}

The model thus correctly simulates the functioning of a rotary kiln under normal conditions, but was also designed to simulate operation under modified conditions, or even with different furnace geometries. It can therefore be used to study the influence of variations in operating parameters (e.g. rotation speed, air or water flowrates, etc.). It 
can also be employed to optimize the rotary kiln pyrolysis process by minimizing coke losses or maximizing the coal feed rate.

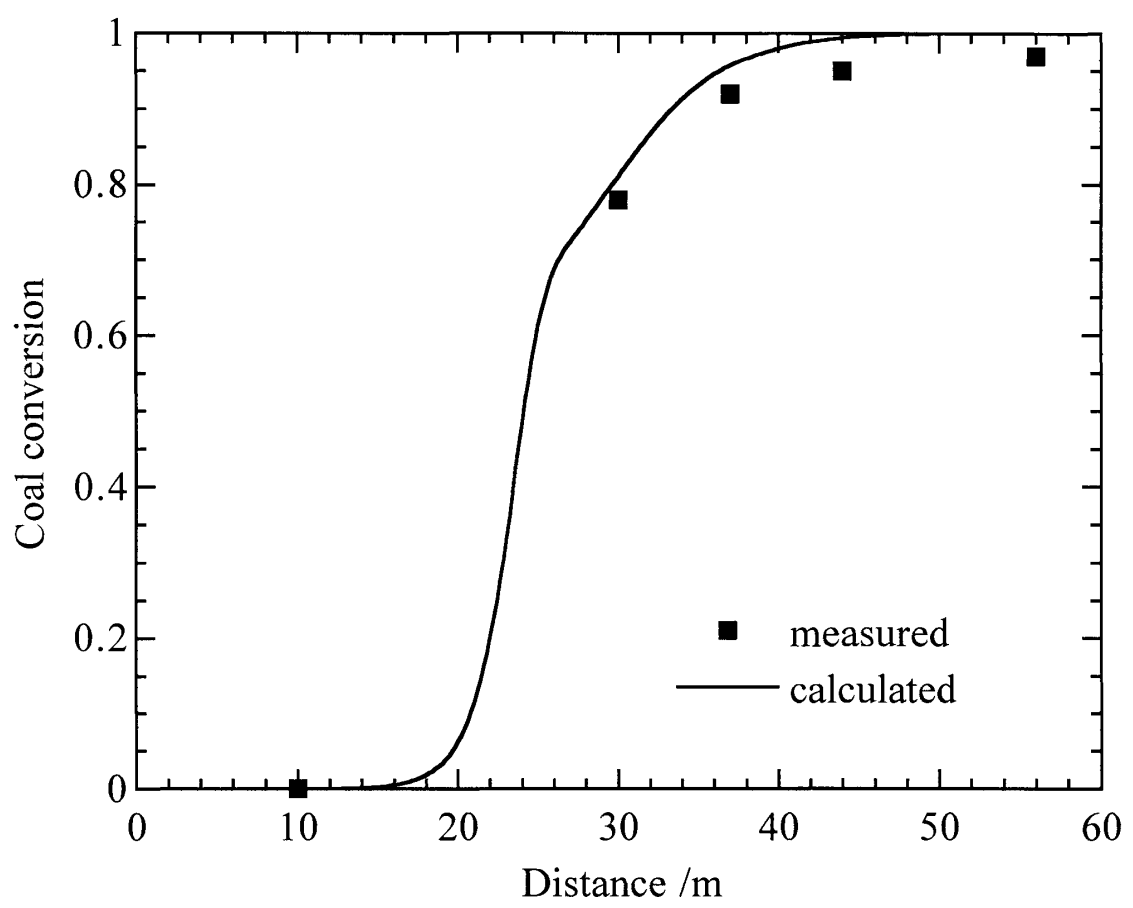

Fig. 8 -Comparison of measured and calculated coal conversion profiles.

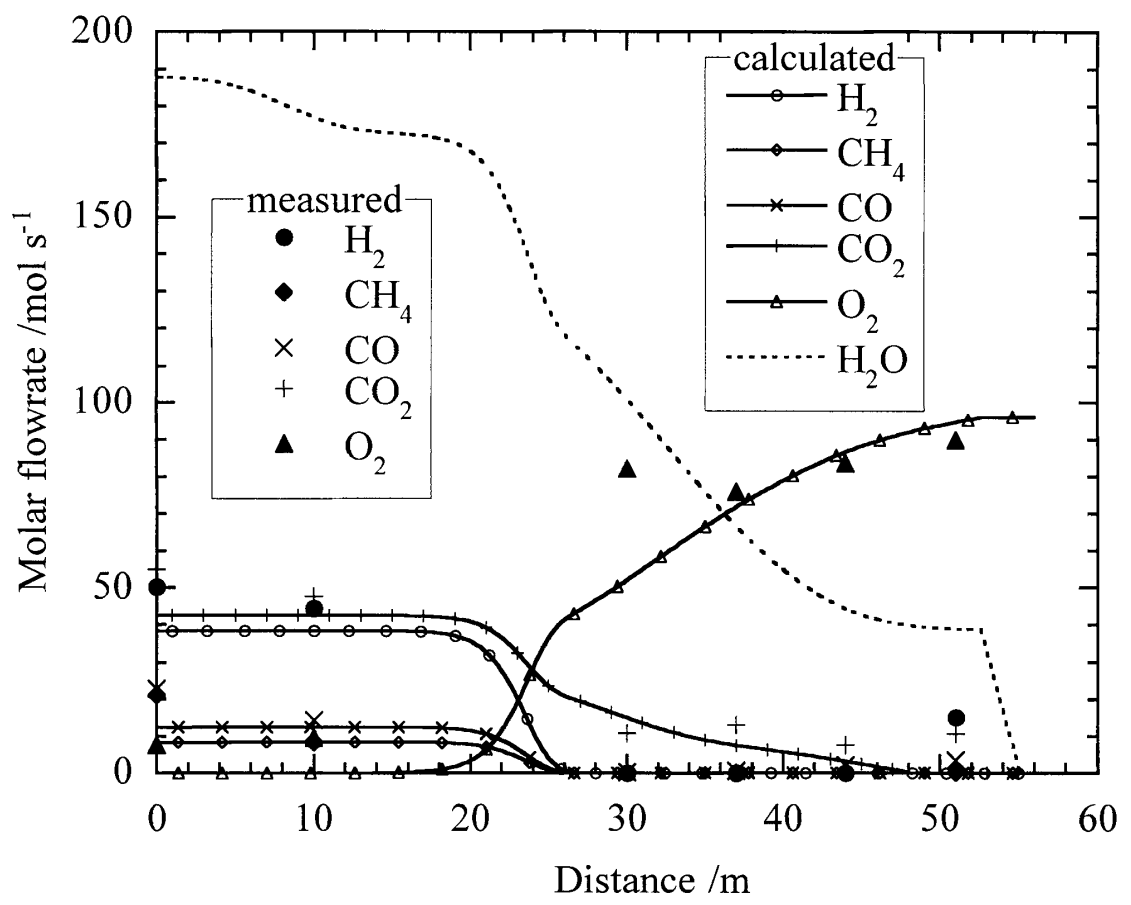

Fig. 9-Comparison of measured and calculated gas flow rate profiles. 
Three parameters, the rotation speed, the air flow and the amount of water injected for coke extinction, are generally used to control the operation of a rotary kiln. For example, these parameters can be modified to correct for the effects of a change in the quality or moisture content of the feed coal. We studied the influence of each of these parameters, and Figure 10 illustrates the effect of the rotation speed on the temperature profiles.

When the rotation speed is raised, the solid flowrate increases and the pyrolysis rate decreases. The volatile matter combustion zone is then shifted towards the coke end. For rotation speeds of 0.95 and $1.05 \mathrm{rpm}$, the increase in the maximum temperature of the solid enhances coke combustion (by respectively +58 and $+13 \%$ ). This shows that there exists an optimum rotation speed to minimize the combustion of coke.

In order to evaluate the potential of the model for process optimization, a different configuration of the extinction zone was simulated, designed to diminish coke combustion. In the normal configuration, water spraying affects the region between $z=$ 52.8 and $z=55.3 \mathrm{~m}$, with a volume flowrate of water $\Phi_{V, \text { ext }}=2.5 \mathrm{~m}^{3} \mathrm{~h}^{-1}$. For the new configuration, a lower water flow was considered, $\Phi_{V, e x t}=1.5 \mathrm{~m}^{3} \mathrm{~h}^{-1}$, but injected at an earlier stage and spread over a greater length of the kiln, between $z=46.8$ and $z=$ $50.3 \mathrm{~m}$.

Figure 11 shows that, outside the extinction zone, the temperature profiles in the charge and the gas are very little affected by the change. The furnace operation should therefore not be disturbed. In contrast, the calculation indicates a significant decrease in coke combustion, which falls from 2.47 to $1.72 \%$ of the dry coal charge. This new configuration of the extinction zone would thus theoretically provide an increase in process yield of $0.75 \%$. 


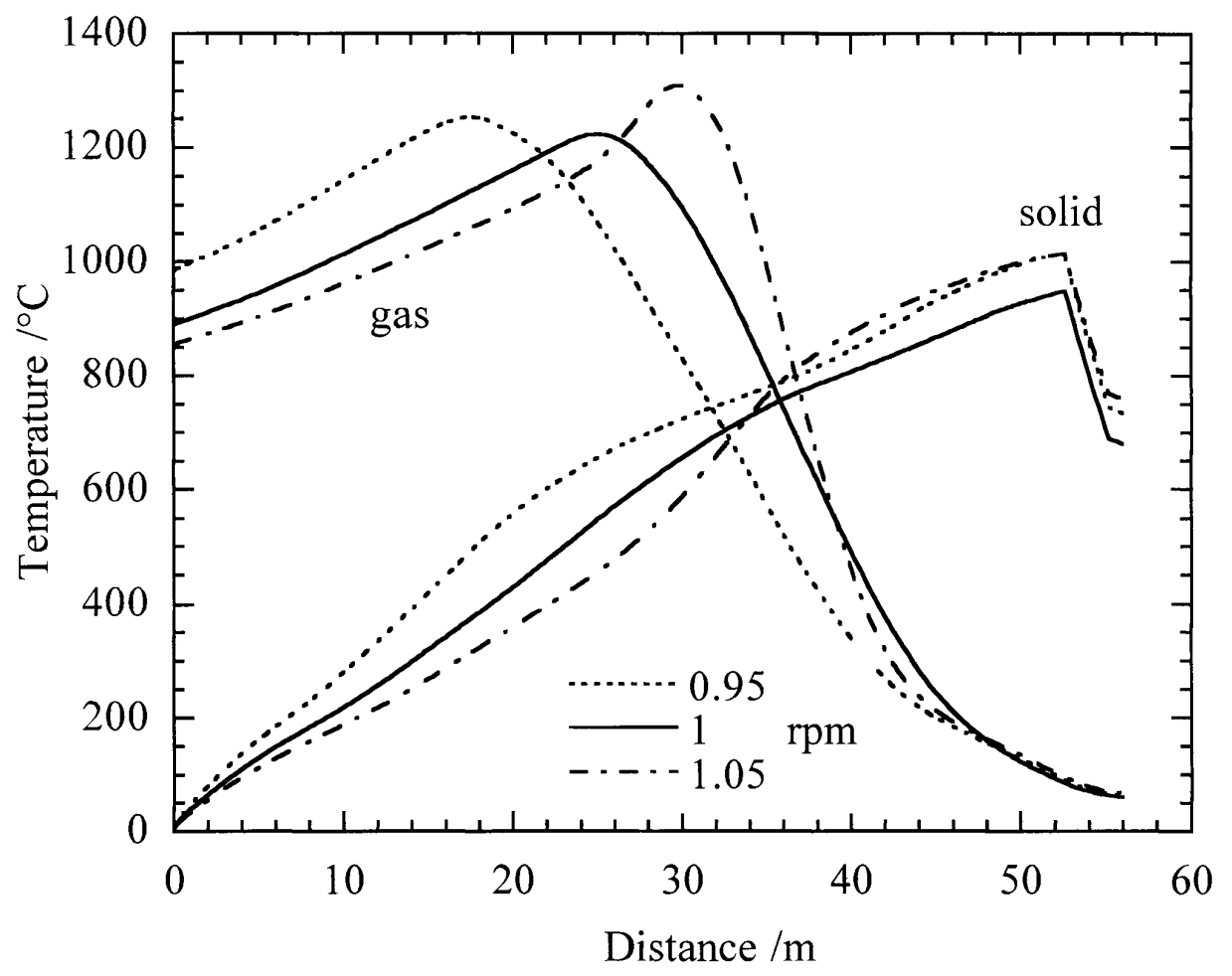

Fig. 10-Influence of the rotation speed on the axial temperature profiles.

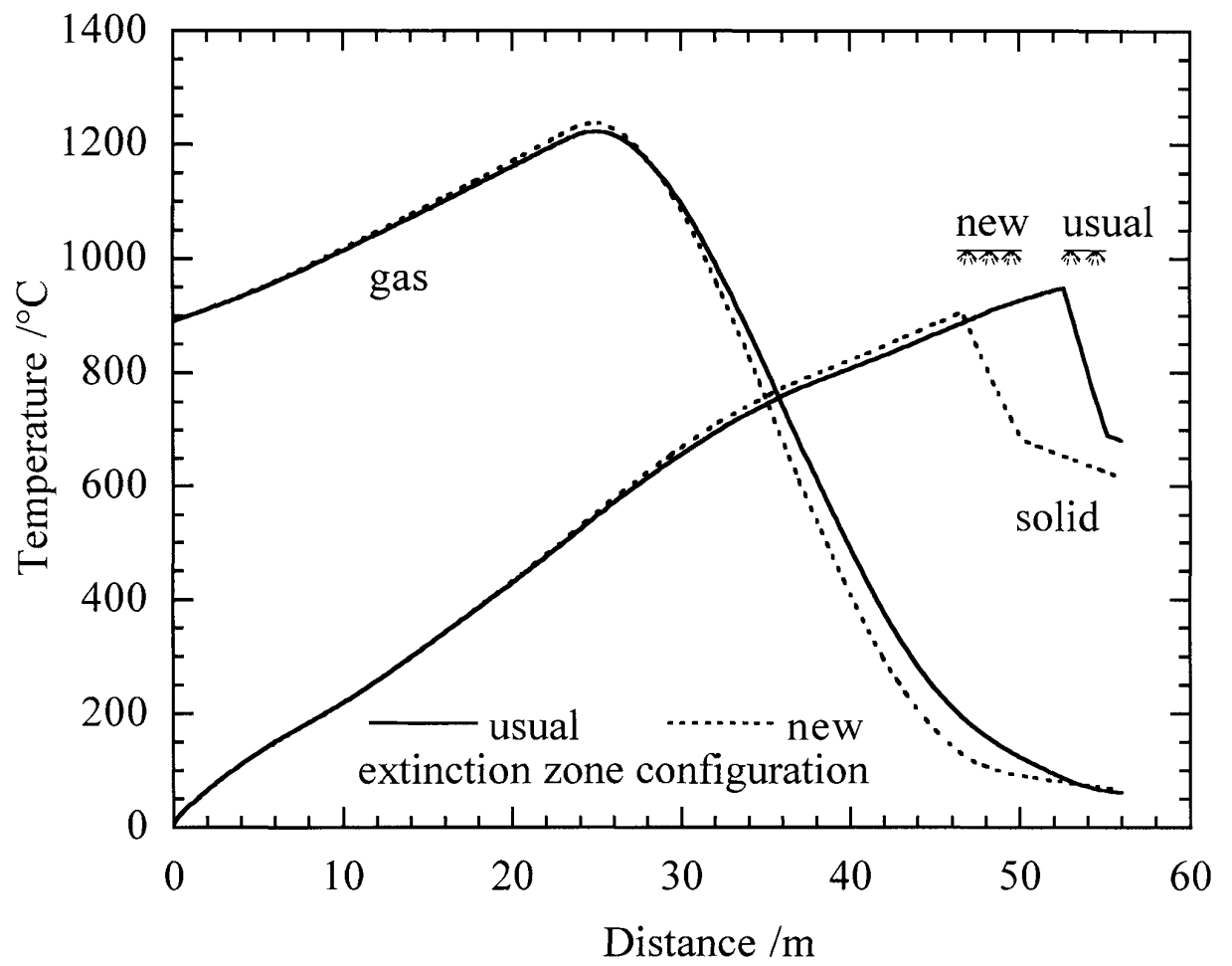

Fig. 11 - Influence of the extinction zone configuration on the axial temperature profiles. 
Based on these calculations, the extinction zone was appropriately modified in the Carling kiln. The results show that, not only was the coke yield effectively increased, but the overall amount of volatile matter removed was reduced, leading to a decrease in the energy content of the fumes. Since the capacity of a boiler heated by the fumes and used to raise steam for another purpose imposed a limitation on the coke production, the lower calorific value of the fumes has also allowed an increase in the amount of coke produced.

\section{CONCLUSIONS}

A mathematical model has been developed for simulating the rotary kiln pyrolysis process. The model describes the majority of the physicochemical and thermal phenomena involved in the process.

The behavior of the charge is described introducing the concept of a reference grain whose behavior is the average of all the grains in the charge. In each radial slice of the kiln, this grain moves successively along the bed surface, against the kiln wall and into the center of the bed. The grain model presented in Part 1 is used to describe the drying, pyrolysis and combustion of this grain in these different stages.

The heat transfer mechanisms are described in detail, including radiation between the gas, the solid and the kiln wall, convection of the solid and gas phases, convective exchanges between the gas, the solid and the wall, and conduction through the wall.

Cracking of the tars and combustion of the volatile species can be considered to be instantaneous, combustion being limited by a lack of oxygen. The combustion of 
coke and its extinction by spraying with water are taken into account both in the gas matter balances and in the grain model.

In order to validate the model, specific measurements of the charge and gas temperatures were made in an industrial kiln and the solid and gas compositions were determined by analyzing samples taken at different positions. The agreement between these measurements and the results of the calculations is satisfactory and confirms the validity of the model.

Finally, the model was used to study the influence of the operating parameters and even to optimize the process. A case examined is the displacement of the coke extinction zone. The model predicts an increase in coke yield of $0.75 \%$ due to this modification, and this has been effectively confirmed in an industrial kiln.

\section{ACKNOWLEDGEMENTS}

The authors are indebted to the Centre de Pyrolyse in Marienau for financial support and the collaboration of its engineers, in particular D. Isler and R. Bertau. Thanks are also due to the Centre National de la Recherche Scientifique which also assisted this work within the framework of the Groupement Scientifique "Pyrolyse du charbon". The authors also thank the staff of the Carling kiln for its collaboration.

\section{NOMENCLATURE}
a thermal diffusivity $/ \mathrm{m}^{2} \mathrm{~s}^{-1}$
$A \quad$ area per unit kiln length $/ \mathrm{m}$
C constant in Eq. [8]
$C_{\varepsilon} \quad$ constant defined by Eq. [6] 


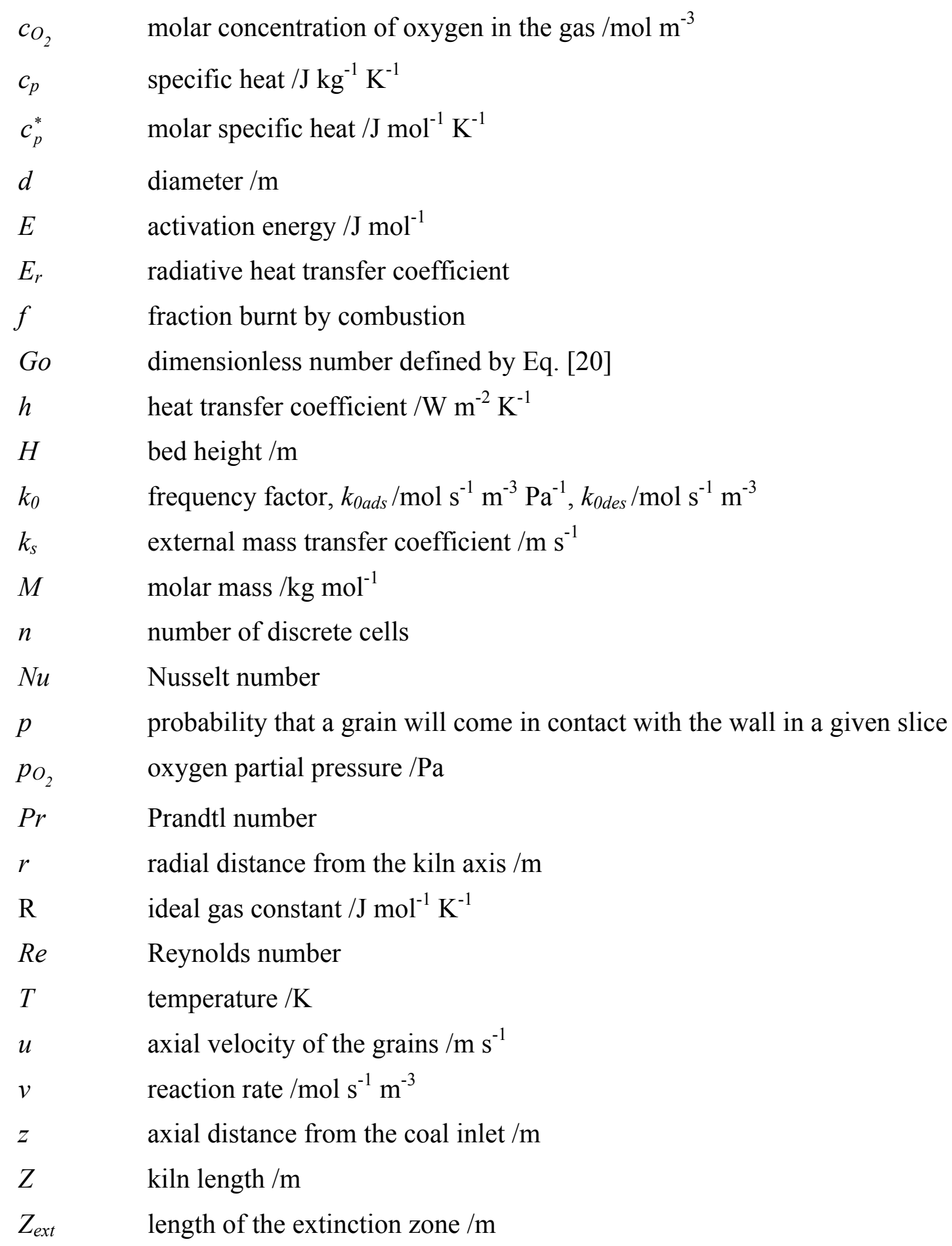

Greek symbols

$\alpha \quad$ filling angle / $\mathrm{rad}$

$\beta \quad$ dynamic rest angle of the charge $/ \mathrm{rad}$

$\Delta \varepsilon \quad$ correction factor for gas emissivity in Eq. [8]

$\Delta_{r} H \quad$ heat of reaction $/ \mathrm{J} \mathrm{mol}{ }^{-1}$ 


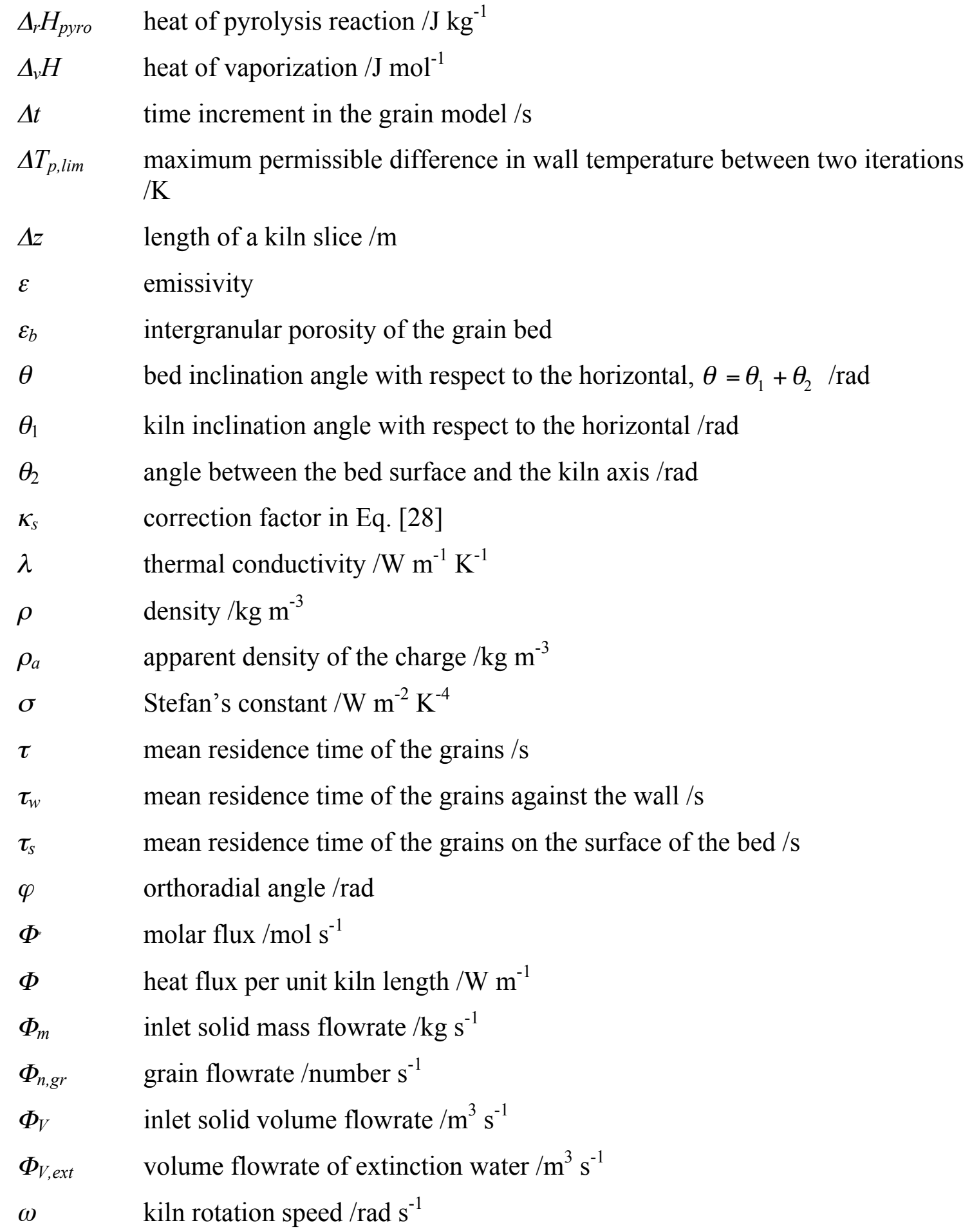

\section{$\underline{\text { Subscripts }}$}

ads adsorption

$c_{g s}, c_{g w}, c_{w a}$ gas/solid, gas/wall, wall/atmosphere convection

$c_{w s} \quad$ wall/solid contact 


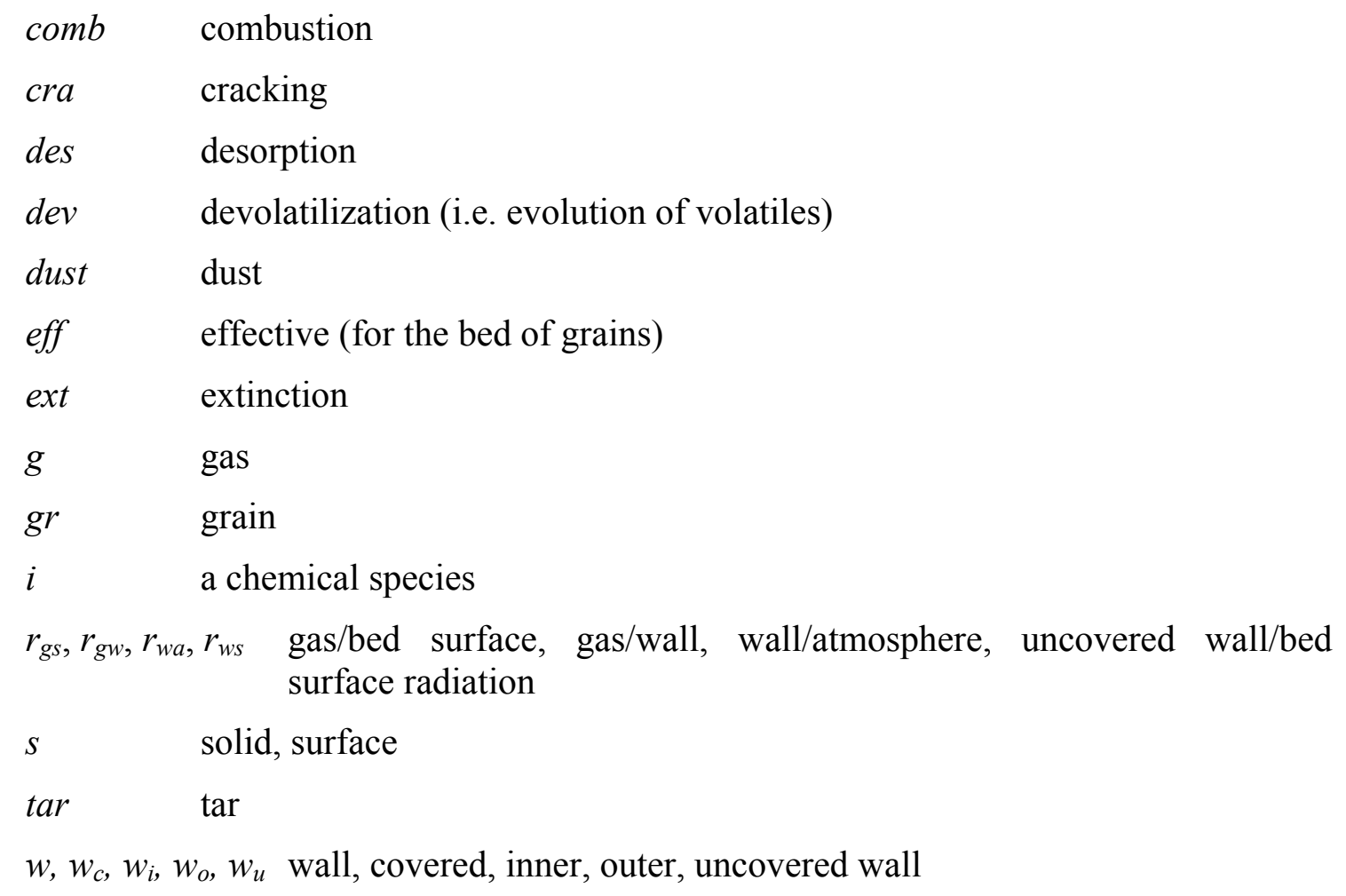

\section{REFERENCES}

1. A. Manitius, E. Kurcyusz, and W. Kawecki: Ind. Eng. Chem. Process Des. Dev., 1974, vol. 13, pp. 132-142.

2. V. Venkateswaran and J.K. Brimacombe: Metall. Trans., 1977, vol. 8B, pp. 387398.

3. G. Dumont and P.R. Belanger: Ind. Eng. Chem. Process Des. Dev., 1978, vol. 17, pp. 107-114.

4. J. Perron, V. Potocnik, and R.T. Bui: Int. Symp. Reduction and Casting of Aluminium Proc., Pergamon Press, New York, Montreal, 1988, pp. 87-98.

5. D.G. Brooks: Light Metals 1989 Proc., TMS, 1989, pp. 461-469. 
6. F. Patisson, E. Lebas, F. Hanrot, D. Ablitzer, and J.-L. Houzelot: Metall. Mat. Trans., Part 1 submitted, ref : 99-20-B.

7. H. Heinein, J.K. Brimacombe, and A.P. Watkinson: Metall. Trans., 1983, vol. 14B, pp. $207-220$.

8. E. Lebas, F. Hanrot, D. Ablitzer, and J.L. Houzelot: Can. J. Chem. Engng., 1995, vol. 73 , pp. 173-180.

9. H. Kramers and P. Croockewit: Chem. Engng. Sci., 1952, vol. 1, pp. 259-265.

10. F. Hanrot: Doctorate Thesis, Institut National Polytechnique de Lorraine, Nancy, 1992.

11. H.C. Hottel and A.F. Sarofim: Radiative transfer, Mc Graw-Hill, New York, 1967.

12. J.P. Gorog, T.N. Adams, and J.K. Brimacombe: Metall. Trans., 1981, vol. 12B, pp. $55-69$.

13. P.V. Barr: Ph.D. Thesis, University of British Columbia, Vancouver, 1986.

14. P. V. Barr, J.K. Brimacombe, and A.P. Watkinson: Metall. Trans., 1989, vol. 20B, pp. 403-419.

15. J. Perron: Ph.D. Thesis, Université de Montréal, Montreal, 1990.

16. A. Saas: I \& EC Proc. Des. Dev., 1967, vol. 6, pp. 532-535.

17. J.K. Brimacombe and A.P. Watkinson: Metall. Trans., 1978, vol. 9B, pp. 201-219.

18. G.A. Ketslakh and I.P. Tsibin: Ogneupory, 1978, vol. 1, pp. 17-19.

19. F. Kreith and W.Z. Black: Basic heat transfer, Harper and Row, New York, 1980.

20. S.H. Tsheng: Ph.D. Thesis, University of British Columbia, Vancouver, 1978. 
21. S.H. Tsheng and A.P. Watkinson: Can. J. Chem. Engng., 1979, vol. 57, pp. 433442.

22. M.N. Ozisik: Heat transfer, Mc Graw-Hill, Montreal, 1985.

23. P. Zehner and E.U. Schlünder: Chem. Ing. Techn., 1972, vol. 44, pp. 1303-1308.

24. E. Lebas: Doctorate Thesis, Institut National Polytechnique de Lorraine, Nancy, 1995.

25. J. Lahouste and P. Payen: 6th Int. Conf. on Coal Science Proc., Munster, 1965, pp. $1-10$

26. W.R. Hesp and P.L. Waters: Ind. Eng. Chem. Prod. Res. Develop., 1970, vol. 9, pp. 194-202.

27. W.Y. Wen and E. Cain: Ind. Eng. Chem. Process Des. Dev., 1984, vol. 23, pp. 627637.

28. M.A. Serio: Ph.D. Thesis, MIT, Cambridge, 1984.

29. M.A. Serio, A.P. Peters, and J.B. Howard: Ind. Eng. Chem. Res., 1987, vol. 26, pp. 1931-1838.

30. K.R. Doolan, J.C. Mackie, and R.J. Tyler: Fuel, 1987, vol. 66, pp. 572-578.

31. P. Barbé, F. Battin-Leclerc, and G.M. Côme: J. Chim. Phys., 1995, vol. 92, pp. 1666-1692.

32. R.J. Kee, F.M. Rupley, and I.A. Miller: Chemkin II. A Fortran chemical kinetics package for the analysis of gas phase chemical kinetics, Sandia National Laboratories, 1993, SAND 89-8009B.

33. R.H. Essenhigh: Ind. Eng. Chem., 1965, vol. 57, pp. 32-43. 
34. W.E. Ranz and W.R. Marshall: Chemical Engineering Progress, 1952, vol. 48, pp. 141-146 and 173-180.

35. K.W. Li: AIChE J., 1974, vol. 20, pp. 1017-1020. 